\title{
Virtual Voice Assistant Applications Improved Expressive Verbal Abilities and Social Interactions in Children with Autism Spectrum Disorder: A Single-Subject Experimental Study
}

Mohammed F Safi ( $\sim$ slpmfsafi@gmail.com ) UAEU https://orcid.org/0000-0003-3451-3894

Badriya Al Sadrani

UAE University: United Arab Emirates University

Ashraf Mustafa

UAE University: United Arab Emirates University

\section{Research article}

Keywords: Autism Spectrum Disorder, virtual voice assistants, language skills, social skills, artificial intelligence, children

Posted Date: March 3rd, 2021

DOI: https://doi.org/10.21203/rs.3.rs-269745/v1

License: (c) (1) This work is licensed under a Creative Commons Attribution 4.0 International License.

Read Full License 


\title{
Virtual Voice Assistant Applications Improved Expressive Verbal
}

\section{Abilities and Social Interactions in Children with Autism \\ Spectrum Disorder: A Single-Subject Experimental Study}

\author{
Mohammed F. Safi ${ }^{1}$, Badriya Al Sadrani ${ }^{2}$ and Ashraf Mustafa ${ }^{2}$ \\ ${ }^{1}$ Department of Speech Language Pathology, College of Medicine and Health Sciences, United Arab Emirates \\ University, Al Ain. UAE. \\ ${ }^{2}$ Special Education, College of Education, United Arab Emirates University, Al Ain. UAE.
}

Correspondence should be addressed to Dr. Mohammed F. Safi; [msafi@uaeu.ac.ae]

\begin{abstract}
(317 words)
Background: Children with autism spectrum disorder (ASD) tend to have communication and social interaction deficits. Their impaired communication is derived from difficulties in acquiring language. The use of interactive technologies has been demonstrated to enhance verbal and non-verbal communication, as well as the social interaction tendencies of children with ASD. Artificial intelligence has played a growing role in the habilitation of children with ASD. However, little research exists on the possible roles and effectiveness of virtual voice assistants in developing language and social skills in children with ASD. This study examined the effects of using a voice assistant in children with ASD on two outcomes: speech skills (expressive verbal vocabulary and production of short phrases) and social interaction skills (playing/sharing).
\end{abstract}

Methods: An interventional single-case design study was used to explore this concept using three children with ASD between the ages of 4 and 11 years. The participants used an accessible virtual voice assistant, Apple's Siri, for three months. Pre- and post-intervention questionnaires and semi-structured interviews with mothers were administered to measure the communication and social interaction skills of the participating children.

Results: Participant One, Two and Three showed a notable improvement in the total number of correct words produced with fewer attempts during the VVA intervention compared with the baseline phase. Further, all participants showed increases in the social interactions in the intervention phase, compared with the baseline phase. Finally, all the mothers noted improvement in their children's speech intelligibility and social interactions.

Conclusions: Results showed that the virtual voice assistant had positive effects on the speech and social interaction skills of children with ASD. The findings of this study implied that children with ASD can use readily available voice assistant software to improve their speech and social interaction skills. Furthermore, this study's findings could be used to develop strategies to increase the availability of artificial intelligence infrastructure in schools and homes to help children with ASD.

Keywords: Autism Spectrum Disorder; virtual voice assistants; language skills; social skills; artificial intelligence; children 


\section{Introduction}

Autism Spectrum Disorder (ASD) is a developmental disorder that affects the way individuals interact with their environment and how they communicate with others. Children with ASD have difficulties initiating or taking turns in conversations. ASD is considered a spectrum of disorders, because the degree of impairment differs from one individual to another. Consequently, ASD management strategies should be individually tailored [1]. One way to achieve this is through the use of interactive technologies. Several interventions, both clinical and non-clinical, using interactive technologies have been tested on children, with varying degrees of success $[2,3,4,5,6]$. In particular, applying artificial intelligence in interventions and blending this with human interaction has been widely studied in the past decade, and recent advances in information communication technology continue to facilitate novel methods that attract renewed attention from practitioners [7]. These research avenues show much promise, and research into the widespread application of such technology for managing ASD clearly represents the next frontier for providing support to children with ASD.

Autism Spectrum Disorders comprises a range of severe developmental disorders that disrupt social relationships, communication, play, and academic skills and usually lead to life-long disability [8]. According to the Diagnostic and Statistical Manual of Mental Disorders [9], ASD is one of 20 types of neurodevelopmental disorders (NDD) that are characterized by a group of symptoms that share a common history and course. NDDs, including ASD, are heterogeneous disorders, thus indicating that not all patients manifest all possible symptoms, and many symptoms are shared with other disorders. $[10,11]$ noted that ASDs are complex NDDs characterized by qualitative impairments in three domains: social interaction; communication; and repetitive, stereotyped behavior. Thus, ASD influences how people communicate and behave due to atypical brain development.

Tracking the prevalence of ASD poses unique challenges, as the symptoms are heterogenous, and no biological diagnostic markers can be detected. Global studies have identified the average prevalence of ASD to be between $1 \%$ and 2\% [12]. [13] demonstrated that 58 per 10,000 children were noted to have characteristics of ASD in a study that used an autism screening questionnaire. In a follow-up using a clinical interview conducted as part of the same study, [13] demonstrated that the weighted prevalence was estimated to be 29 per 10,000 for a DSM IV diagnosis of pervasive developmental disorder.

Many children with ASD exhibit developmental speech and language deviations and delays that are a result of intellectual and linguistic impairments [14]. The severity of language deviations and delays significantly varies in terms of symptoms. Studies have indicated that children with ASD a) present delayed and limited development of phonology and syntax [14]; b) have impaired comprehension and use of personal pronouns, errors of verb tense marking, impaired use of articles and conjunctions, and diminished use of closed class words, especially in the early stages of language acquisition [15]; c) use stereotypical, echolalic, and bizarre language[14]; d) have a fundamental impairment in conceptual knowledge acquisition [16]; e) often produce stereotypical and monotonous sounds and experience difficulties using words such as pronouns[14]; f) have limited depth of word knowledge [17]); g) experience difficulties integrating phonological information [18]; h) consolidate new word knowledge less readily [19]; i) repeat questions and take idioms and axioms as literal [20]; and j) have difficulties engaging in conversations as a result of these impairments [21]. 
Virtual voice assistants (VVA) are interactive mechanisms that can interpret people's speech and respond in a synthesized voice. VVAs can interact with humans through such actions as answering basic questions, telling jokes and stories, singing, and performing simple math calculations [22]. At present, there is an inadequate body of research exploring the role of VVAs in helping children with ASD learn effective communication skills, despite the significant promise that such an approach holds. Although the fact that language difficulties are common in children with ASD is widely known, the application of artificial intelligence in the teaching language is limited [22]. Most research has focused primarily on the roles of augmented reality, virtual reality, and games in relation to social and communication skills $[23,24,25]$. Furthermore, children's interpretations of non-verbal cues and the effects of augmented reality have also been emphasized [26].

The wide availability of VVA offers potential benefits for improving social and communication skills in children with ASD, as VVA technology can enhance their quality of life by helping them to integrate into society more effectively. However, no studies have been found to date that investigate this topic. With improvements in VVA voice quality and the availability on most smart device platforms, such as smartphones, tablets, and computerswhich are accessible and easy to use at home or school [22,242], VVAs could be a daily asset for children with ASD who have difficulties with social interactions and communication [22].

In many areas worldwide, the resources necessary to improve communication and speech skills, such available speech therapists and special education teachers; are often inaccessible. Consequently, to improve these skills in children with ASD, there is a need for innovative methods using tools and devices that are readily available in their home environment. However, there is currently a lack of research, due to the recency of technological developments. Thus, this study aimed to address this imbalance and explore the use of artificial intelligence-particularly the recent developments in VVAs technology-to facilitate the development of language and social skills in children with ASD.

This study will be of significance for a number of reasons. By providing insight into new methods to develop language skills in children with ASD, it takes a step toward creating an equal and intelligently adaptive playground for all children. Stakeholders could use this study's results to develop strategies for increasing the availability of artificial intelligence infrastructure in schools and homes to help these children. For teachers, the study will serve as a benchmark in the application of artificial intelligence. The study will also be beneficial to practitioners who work with children with ASD. Furthermore, it will serve as a guiding framework on the use of VVAs in helping children develop spoken language and provide real examples of how VVAs can be used successfully in this manner.

This study was guided by a conceptual framework which proposed that the interactive nature of VVAs has a positive direct impact on speech development, interpretation of non-verbal cues, and social interaction skills in children with ASD. VVAs can be used as tools that provide children with a chance to listen and respond verbally, thus improving their ability to produce intelligible verbal responses. Furthermore, interaction with virtual characters can also serve to expose children to non-verbal cues, which can improve their ability to interpret non-verbal cues through repetition.

Additionally, it has been argued that VVAs can act as partners with whom children with ASD can interact, which may boost their social skills when interacting with adults and other children. In this framework, the strength of the correlation between the independent variable (VVAs) and dependent variables (expressive verbal abilities and social interaction skills) will 
be influenced by each child's age and degree of impairment, which serve as the moderating variables. The conceptual framework is illustrated in Figure 1.

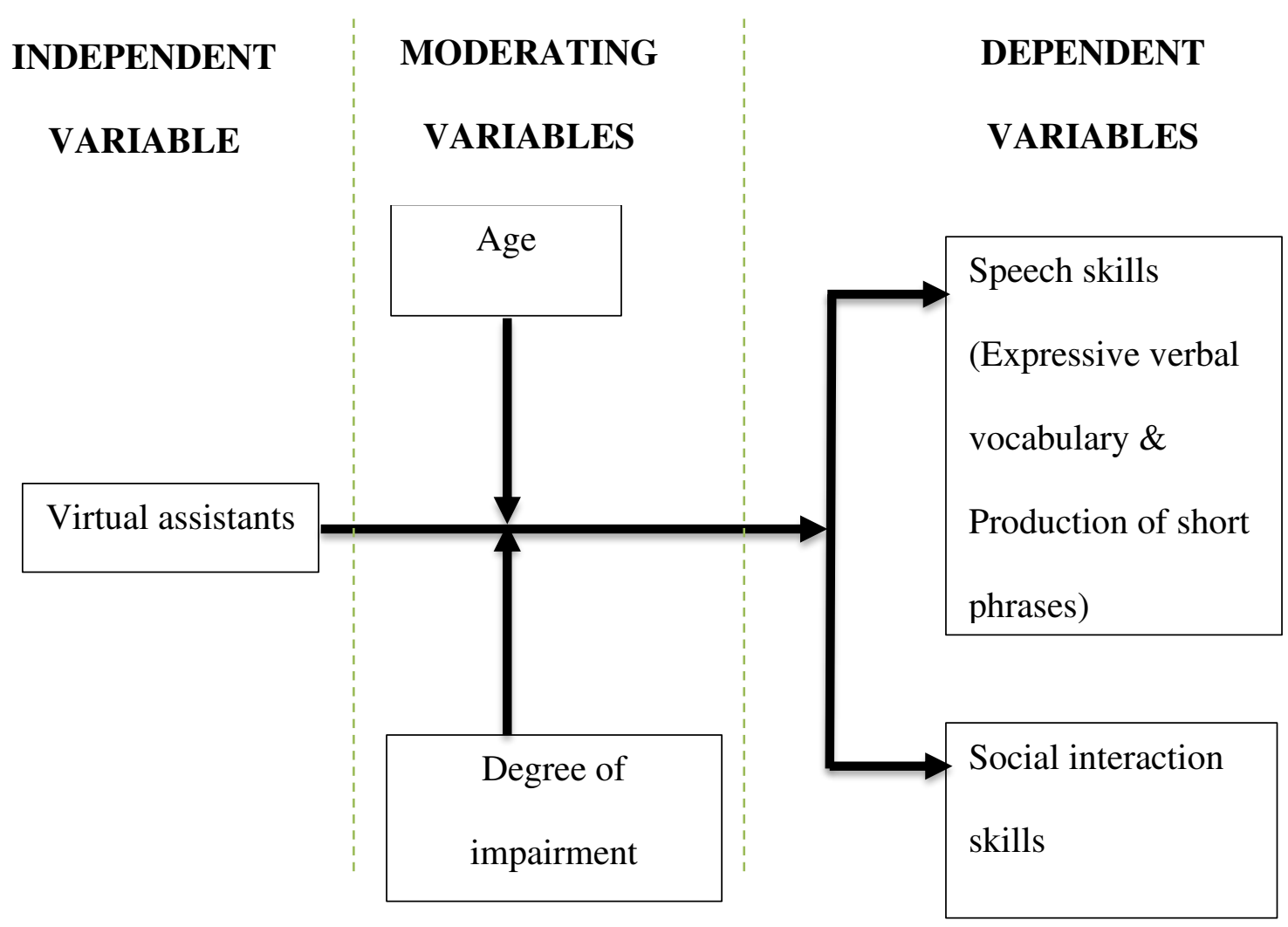

Figure 1. The study's conceptual framework.

The following research questions were addressed in the present study:

1. What are the effects of expressive language stimulation activities using VVAs on expressive vocabulary skills in children with ASD?

2. What are the effects of expressive language stimulation activities using VVAs on the social interaction skills in children with ASD?

3. What are the effects of expressive language stimulation activities using VVAs on the intelligibility of children with ASD, as rated by their mothers?

\section{Material and Methods}

\section{Research Design}

The study applied a single-case research A-B-A design, which involves the manipulation of the independent variable(s) over time to determine how such variables impact the dependent variable(s), thus allowing for hypothesis testing [28]. This research was interventional and aimed to determine the effectiveness of an expressive language intervention using a VVA by assessing participants before the intervention and comparing those assessments with measurements taken during various study phases [29]. The data obtained prior to the intervention acted as a control (baseline). This research design allows for vigorous experimental evaluation of an intervention's effectiveness while relying on one or only a few 
participants as opposed to obtaining data from a large pool of samples. Although singlesubject experimental studies use a small sample size, such a design can be preferable as a source of rich information on each participant [30], can be used in making causal inferences [29], and seeks to obtain data from children with ASD before, during, and after implementing an intervention using an A-B-A design.

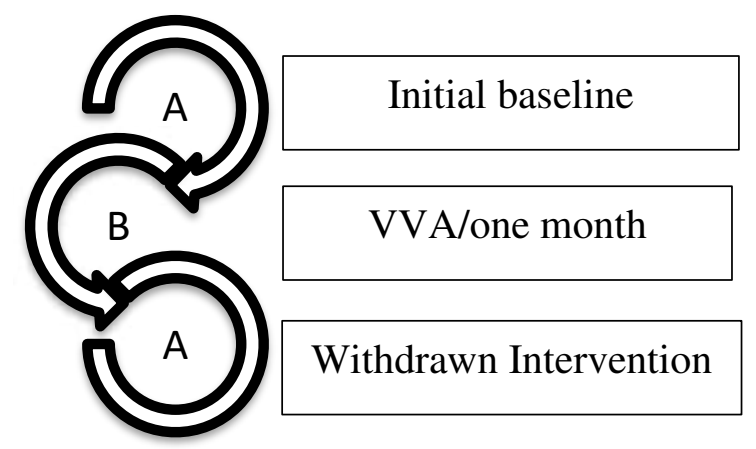

Figure 2. Illustration of the intervention's A-B-A design.

\section{Sample}

This study targeted children who were diagnosed with ASD at around preschool age (4 years). UAEU ethics approval was obtained for this study, and informed consent was obtained from each participant's parents. To confirm participants' ASD diagnoses, the GARS-3 was administered by a qualified speech language pathologist. The selection criteria for participants were a) a valid diagnosis of ASD, b) the presence of an expressive language delay, and c) difficulties with social interactions.

\section{Participants and Setting}

Participant 1 (P1): A four-year-old male enrolled in kindergarten at the time of the study that did not provide any special education support. He did not receive any speech language therapy while participating in this study. His autism index was 84, as measured by the GARS-3 [31], equivalent to Level Two in the DSM IV. Regarding receptive language abilities, he was able to follow instructions if they were broken down into one- or two-step commands.

Participant 2 (P2): A six-year-old male enrolled in the first grade at the time of the study. $\mathrm{He}$ had received special education support, as well as speech therapy and behavioral modification sessions in the past; however, he did not receive any therapy while participating in this study. His autism index was 87, as measured by the GARS-3 [31], equivalent to Level Two in the DSM IV. Similar to P1, P2 was able to follow instructions if they were broken down into short steps.

Participant 3 (P3): An 11-year-old male enrolled in grade six at the time of the study. He had received special education support, as well as speech therapy and behavioral modification sessions in the past; however, he did not receive any therapy while participating in this study. His autism index was 87, as measured by the GARS-3 [31], equivalent to Level Two in the DSM IV. His receptive language abilities were at a level where he able to follow instructions if they were broken down into short steps. 


\section{Procedure}

\section{Phases}

\section{A. Baseline Phase}

The baseline phase involved observing and assessing each child for speech and social interactions over four weeks. During this phase, participants took part in traditional language stimulation sessions with their mothers, using only traditional toys and cards.

To decrease threats to internal validity, a subsequent baseline (A) assessment period that lasted four weeks was also implemented following the intervention phase. This assisted in confirming the intervention's effectiveness and whether the changes occurred due to the intervention or another extraneous variable [19]. In this second baseline, the intervention withdrew, and each student was introduced to new words with only his mother's assistance, and not with a VVA.

\section{B. VVA Intervention Phase}

Training parents on the VVA intervention. Each family was provided with an iPad. The three participants were assessed for their ability to use Apple smartphone and tablet devices prior to the intervention. Each of the participants and their mothers were taken through a training session on using VVAs (i.e., Apple's Siri). The first three sessions of the intervention phase (Phase B) were conducted with the researcher, while the remaining sessions were conducted with the children's mothers at their homes. The first session was an introductory training session to provide education on the study's purpose and procedure, as well as to establish a rapport with the child in an informal familiar setting (i.e., home). Then, the mothers were asked to sign the consent form. Initially, neither the children nor their mothers were familiar with Siri. Therefore, the researcher introduced them to Siri and trained them to it by interacting with Siri application informally via the iPad. P3 required an additional training session. During the next two consecutive sessions, the researcher modeled a typical session using VVA for the mothers. The mothers were asked to repeat the demonstration to make sure they understood the concept as well as are able to implement the intervention adequately.

VVA application intervention sessions. Each participant used a VVA (Siri) for two months. Participants took part in two 10-minute interventional sessions per day. Most sessions were conducted after school and during weekends. To reduce threats to the validity of the results, the intervention was administered in the children's natural environment (home) with the same researcher and parent throughout the program [32].

The mothers were required to initiate each intervention session by using Siri before the child (for instance saying, "hey Siri"). Then, the child was given the chance to do the same. If the child did not follow the stimulus, the mother was required to repeat the modeling behavior. If the child did not show interest, the mother was asked to terminate the session and reattempt later that day. If the child was successful in engaging with the stimulus, the mother was required to use the next word or phrase from an assigned list. Figure 3 presents a sample conversation during an intervention session. 


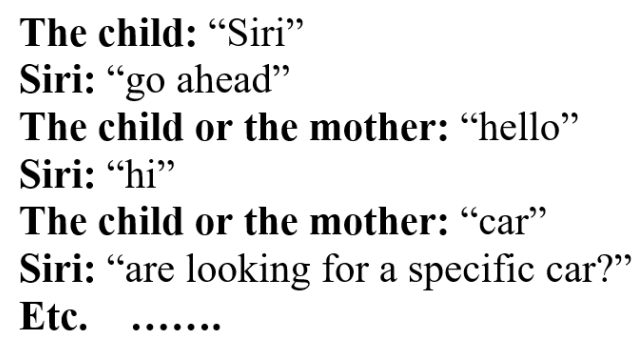

Figure 3. A sample interaction with Siri.

Stimuli sets. Three sets of stimuli were used in this study; Set 1 consisted of eight social words such as "hi" or "hello," Set 2 consisted of nine two-word phrases, and Set 3 consisted of seven three-word phrases.

\section{Response Measurement}

\section{A. Daily Measurments}

Following each session, the parents counted how many times their child verbally produced the assigned words/phrases correctly. This was based on Siri's response. The mothers were required to video record at least one session per day and send it to the researcher.

\section{B. Weekly Progress Measurements}

To monitor each mother's consistency in conducting the sessions, as well as each child's progress, two weekly checklists were used. The Parent Assessment Checklist (PACL) is a weekly checklist that was developed by the researcher and consists of a questionnaire to collect data on parents' consistency in following the intervention procedure as well as the child's ability to use Siri on his own (see Appendix A for details). The Social Assessment Checklist (SACL) was developed by the researcher to monitor progress related to social interactions before the initiation of Phase A and following each phase. The SACL consists of 10 questions to evaluate social aspects of communication (see Appendix B for details).

\section{Data Analysis}

In this study, data analysis involved visual analysis of graphical data, as suggested by Lobo et al. [29]. The data for the three participants were presented graphically, with spaghetti plots for each participant's data. This served to aid in visualization of the data and making valid comparisons. Visual analysis is generally used to determine whether there is a functional relationship between the independent and dependent variables. Each case will be compared to itself. The visual analysis focused on a) slope/trend and b) the total ratio of responses to opportunities. 


\section{Results}

This study was conducted over three months, from September to December 2019. The total number of sessions per child ranged from 22 to 29.

\section{Improvements in Expressive Verbal Skills}

The first research question was "What are the effects of expressive language stimulation activities using VVAs on expressive vocabulary skills in children with ASD?"

P1 showed a notable improvement in the total number of correct words produced with fewer attempts during the VVA intervention (Phase B) compared with the traditional ones (Phase A; see Table 1). Additionally, a visual inspection of Figures 4 and 5 reveals that the number of new words produced was higher in the VVA intervention phase, indicating that VVA contributed to improvements in P1's expressive vocabulary.

Table 1. Total number of attempts and correct words produced for P1.

\begin{tabular}{|l|c|c|c|c|}
\hline & \multicolumn{2}{|c|}{ List 1 } & \multicolumn{2}{c|}{ List 2 } \\
\hline Phase & $\begin{array}{c}\text { Total } \\
\text { Attempts }\end{array}$ & $\begin{array}{c}\text { Total Correct } \\
\text { Words }\end{array}$ & $\begin{array}{c}\text { Total } \\
\text { Attempts }\end{array}$ & $\begin{array}{c}\text { Total Correct } \\
\text { Words }\end{array}$ \\
\hline A & 47 & 28 & 35 & 14 \\
\hline B & 30 & 51 & 28 & 57 \\
\hline A & 40 & 48 & 23 & 29 \\
\hline
\end{tabular}

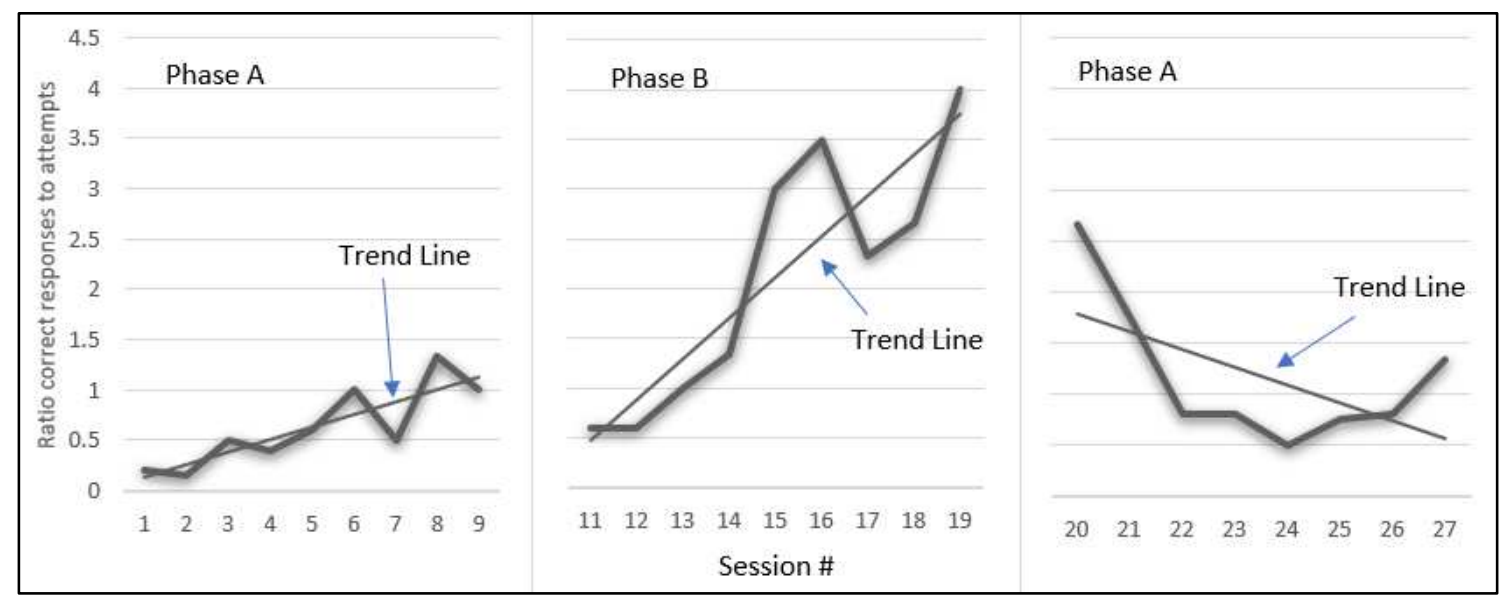

Figure 4. Change in number of correct words produced in relation to attempts per sessions for P1 ( $1^{\text {st }}$ set of words). 


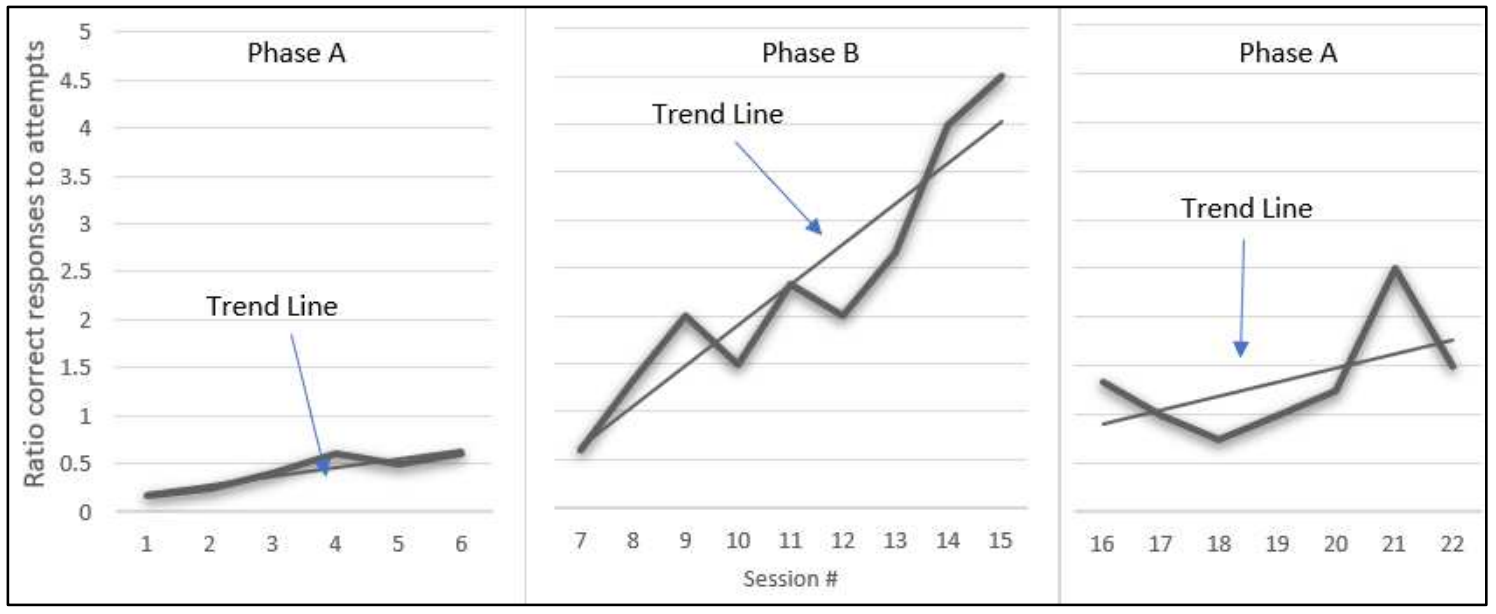

Figure 5. Change in number of correct words produced in relation to attempts per sessions for P1 ( $2^{\text {nd }}$ set of words).

Additionally, P1 demonstrated improvements in developing new expressive words during the VVA intervention (Phase B), compared to the traditional intervention (Phase A; see Figure $6)$.

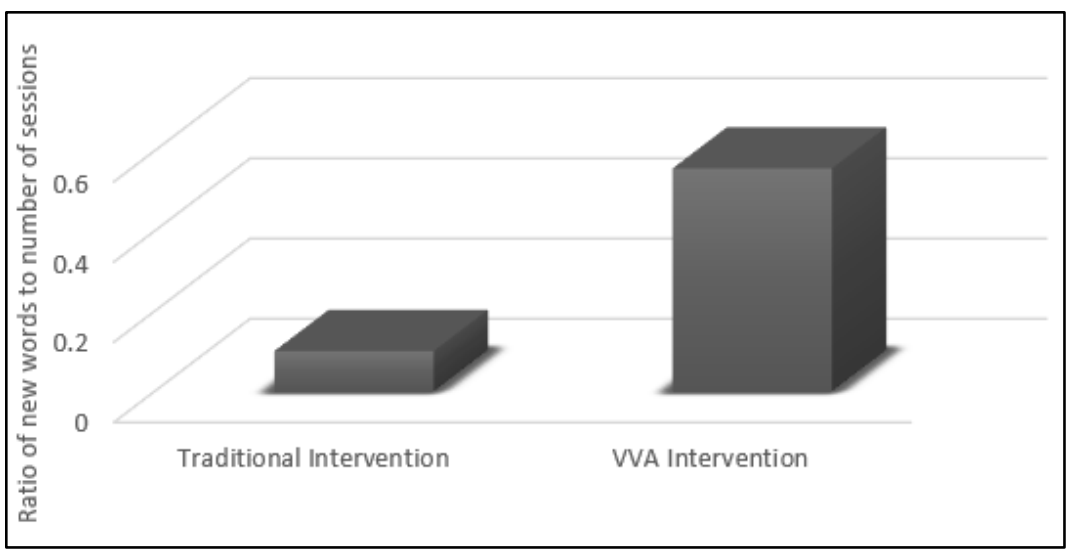

Figure 6. Comparing the ratio of new words produced to number of sessions between the traditional intervention and VVA intervention for P1.

P2 also showed notable improvement the total number of correct words produced with fewer attempts during the VVA intervention (Phase B), compared with the traditional intervention (Phase A; see Table 2). Visual inspection of Figures 7 and 8 reveals that the number of new words produced was higher during the VVA intervention phase, indicating that using the VVA contributed to improvements in P2's expressive verbal vocabulary.

Table 2. Total Attempts and Correct Words Produced for P2.

\begin{tabular}{|lcccc|}
\hline & \multicolumn{2}{c}{ List 1 } & \multicolumn{2}{c|}{ List 2 } \\
\hline Phase & $\begin{array}{c}\text { Total } \\
\text { Attempts }\end{array}$ & $\begin{array}{c}\text { Total Correct } \\
\text { Words }\end{array}$ & $\begin{array}{c}\text { Total } \\
\text { Attempts }\end{array}$ & $\begin{array}{c}\text { Total Correct } \\
\text { Words }\end{array}$ \\
\hline A & 48 & 37 & 56 & 48 \\
B & 30 & 70 & 31 & 76
\end{tabular}




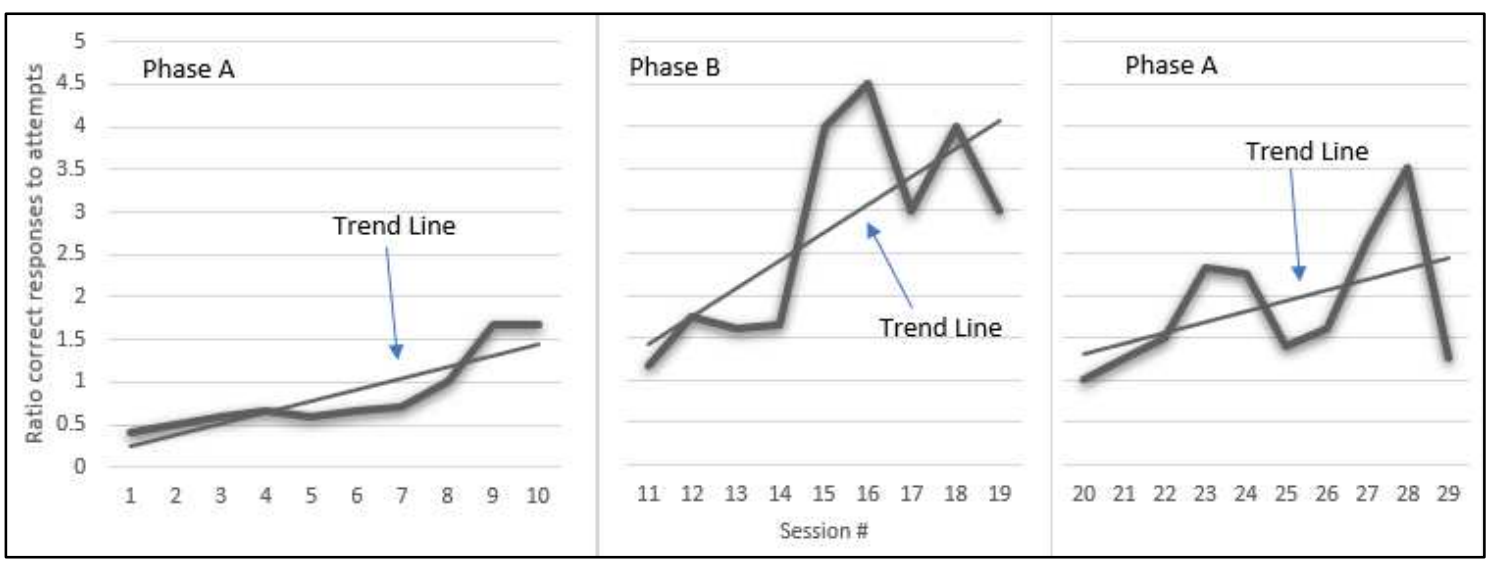

Figure 7. Change in number of correct words produced in relation to attempts per sessions for P2 $\left(1^{\text {st }}\right.$ set of words).

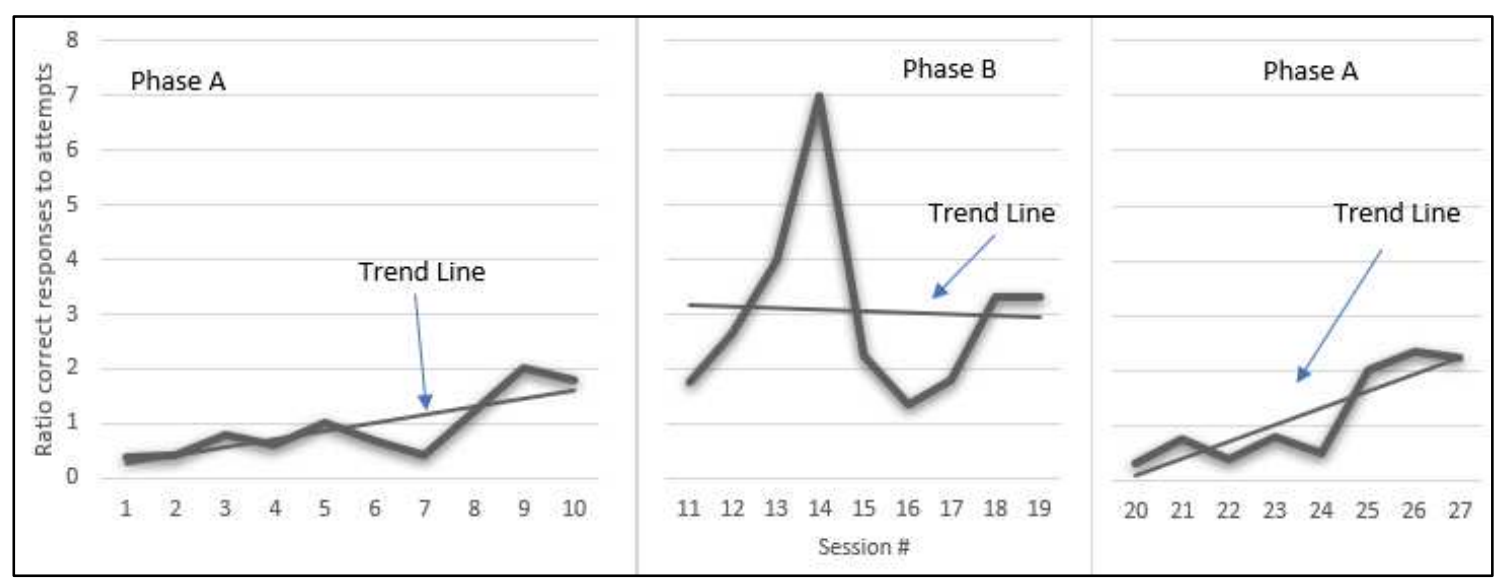

Figure 8. Change in number of correct words produced in relation to attempts per sessions for P2 $\left(2^{\text {nd }}\right.$ set of words).

Like P1, P2 demonstrated an improvement in developing new expressive words during the VVA intervention (Phase B), compared to the traditional intervention (Phase A; see Figure 9). The number of new words produced was significant in the VVA intervention phase; P2 produced five new words, compared to no new words in the first traditional phase and two words in the second traditional phase. 


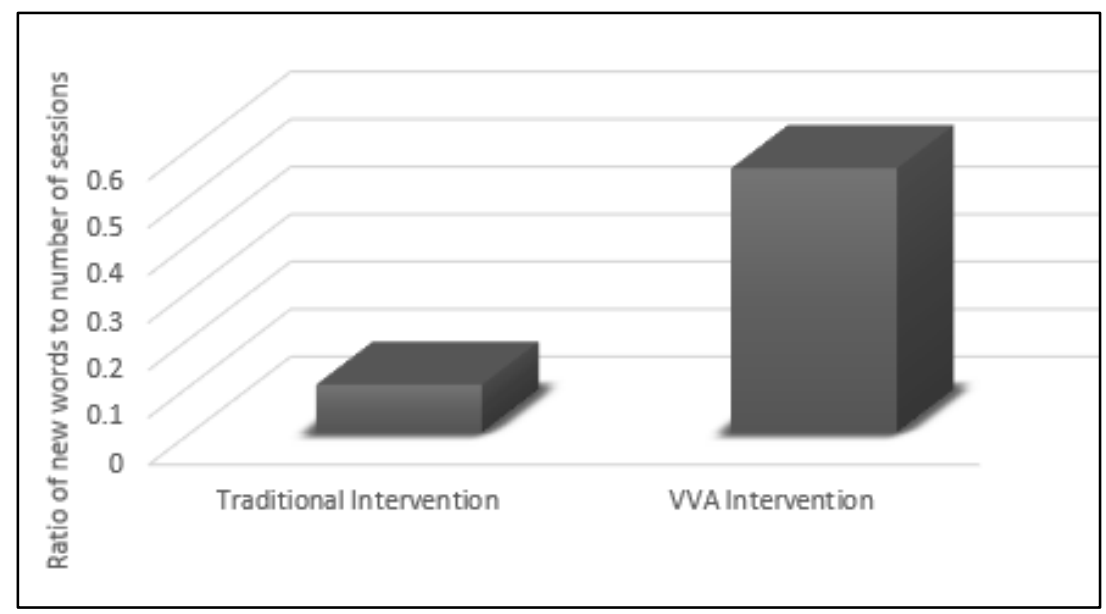

Figure 9. Comparing the ratio of new words produced to number of sessions between the traditional intervention and VVA intervention for P2.

P3 demonstrated similar results. He showed a notable improvement in the total number of correct words produced with fewer attempts during the VVA intervention (Phase B) compared with the traditional ones (Phase A; see Table 3). Visual inspection of Figures 10 and 11 shows that the number of new words produced was higher during the VVA intervention phase.

Table 3. Total attempts and correct words produced for P3.

\begin{tabular}{|lcccc|}
\hline & \multicolumn{2}{c}{ List 1 } & \multicolumn{2}{c|}{ List 2 } \\
\hline Phase & $\begin{array}{c}\text { Total } \\
\text { Attempts }\end{array}$ & $\begin{array}{c}\text { Total Correct } \\
\text { Words }\end{array}$ & $\begin{array}{c}\text { Total } \\
\text { Attempts }\end{array}$ & $\begin{array}{c}\text { Total Correct } \\
\text { Words }\end{array}$ \\
\hline A & 47 & 35 & 65 & 51 \\
B & 19 & 51 & 32 & 63 \\
A & 43 & 49 & 29 & 44 \\
\hline
\end{tabular}

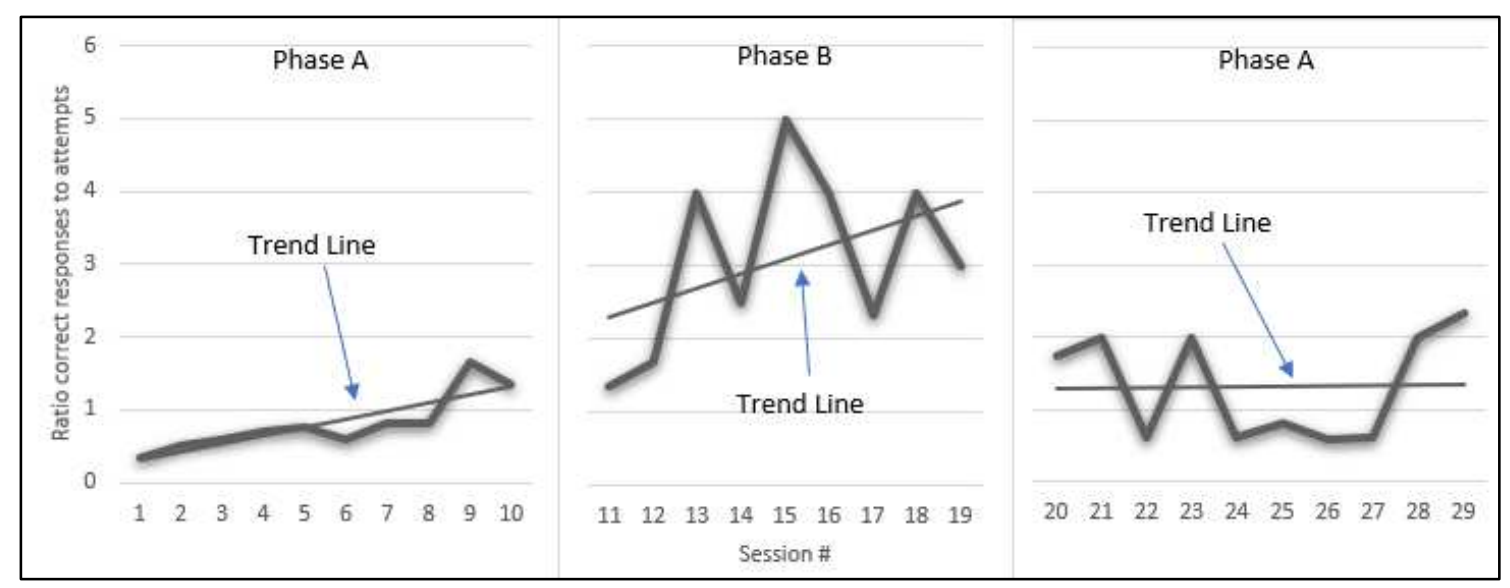


Figure 10. Change in number of correct words produced in relation to attempts per sessions for P3 ( $1^{\text {st }}$ set of words).

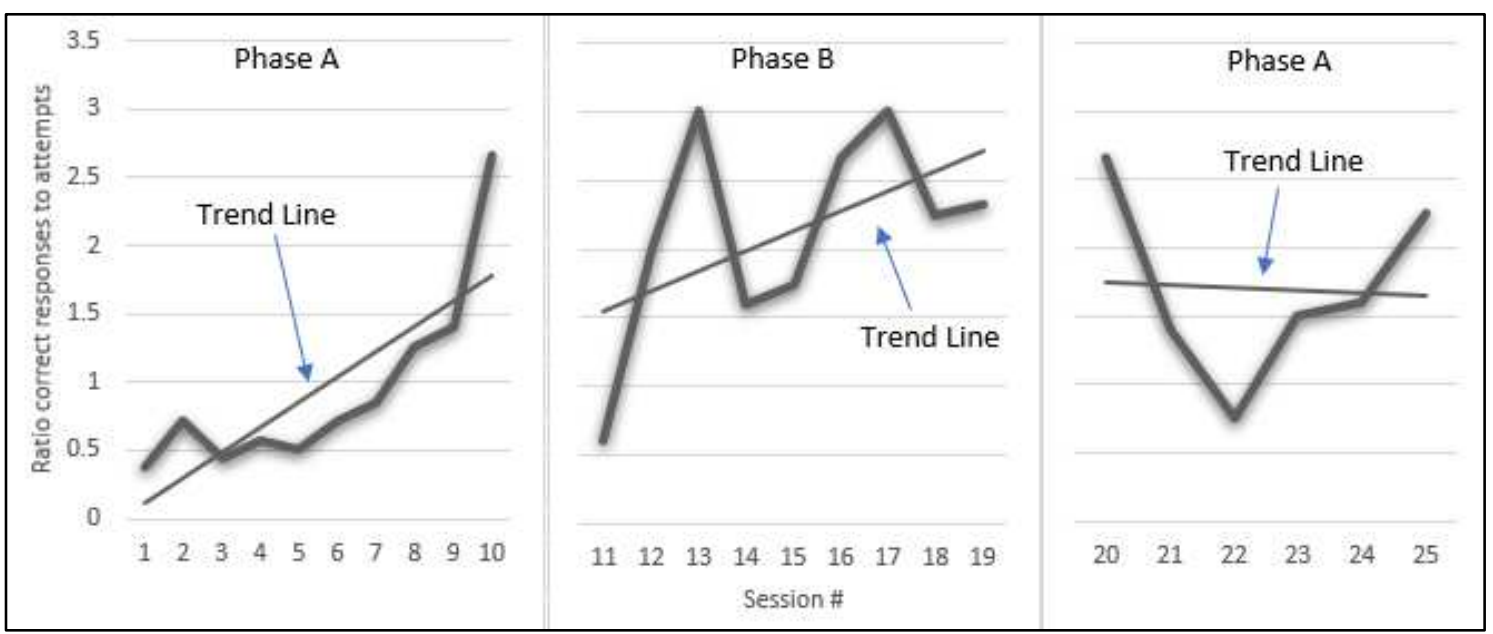

Figure 11. Change in number of correct words produced in relation to attempts per sessions for P3 ( $2^{\text {nd }}$ set of words).

Similar to P1 and P2, P3 demonstrated an improvement in developing new expressive words during the VVA intervention (Phase B), compared to the traditional intervention (phases A; see Figure 12).

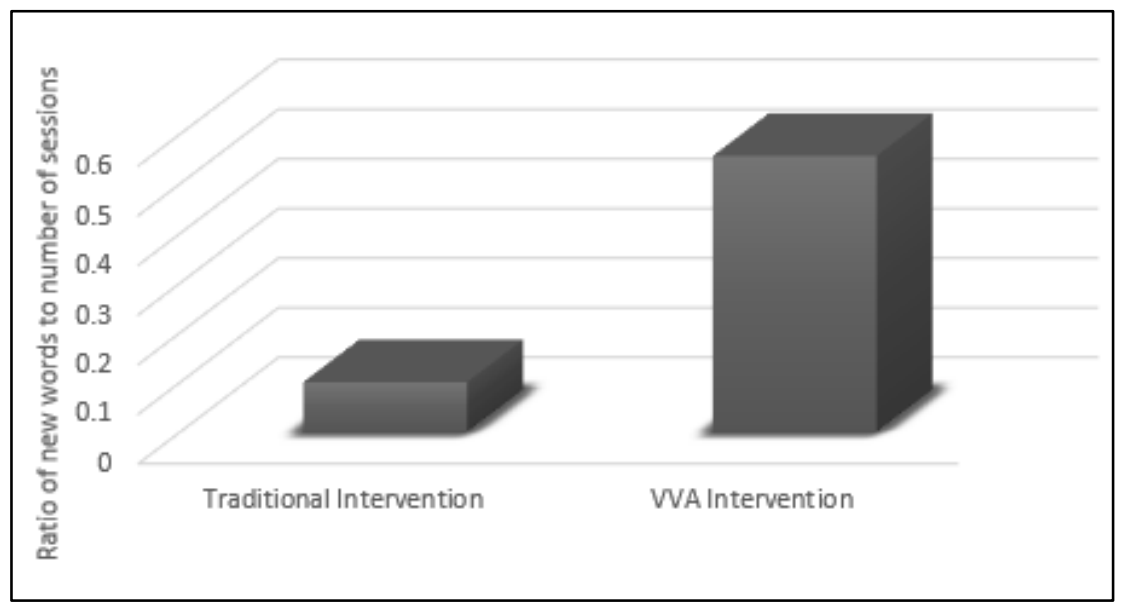

Figure 12. Comparing the ratio of new words produced to number of sessions between the traditional intervention and VVA intervention for P3.

\section{Changes in Social Interaction Skills}

The second question was "What are the effects of expressive language stimulation activities using VVAs on the social interaction skills in children with ASD?" 
To answer this question, the results from the SACL were used. Visual analysis was also used to investigate changes in social interactions during VVA use. The bar charts for P1, P2, and P3 in Figures 13, 14, and 15, respectively, show increases in the social interactions of all participants in the intervention phase, compared with the baseline. These results indicated that the use of artificial interactive technological programs, such as VVAs, could produce a small yet positive influence on participants' social interaction skills.

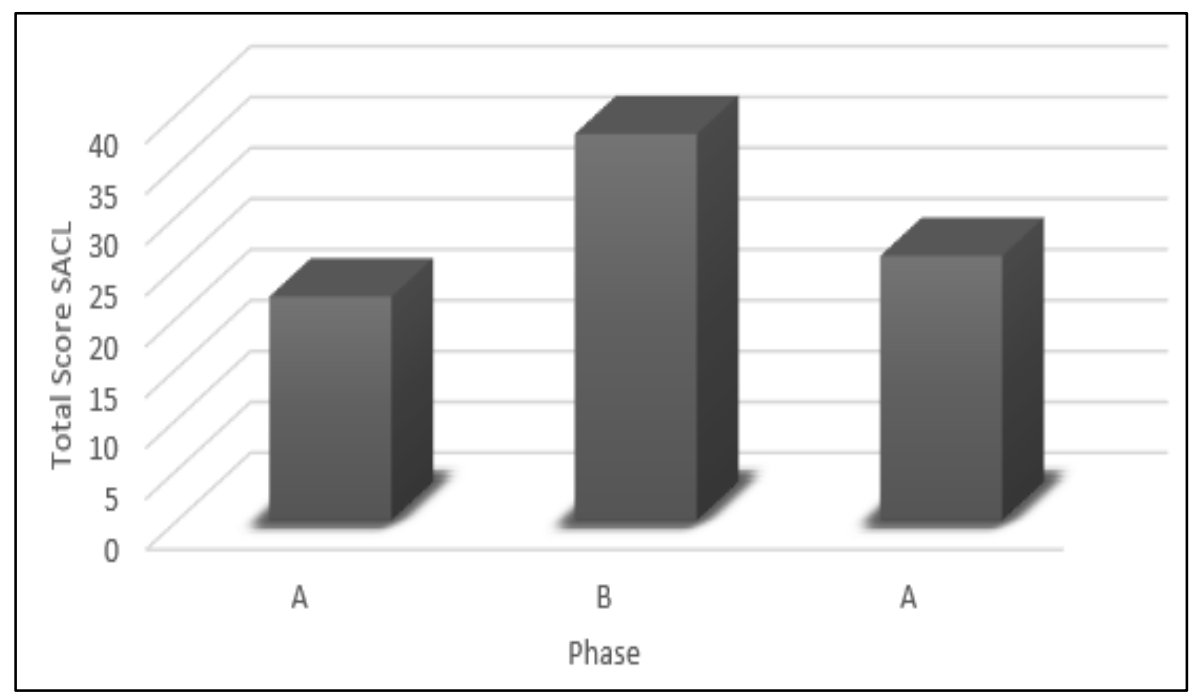

Figure 13. Social Assessment Checklist (SACL) scores per phase for P1.

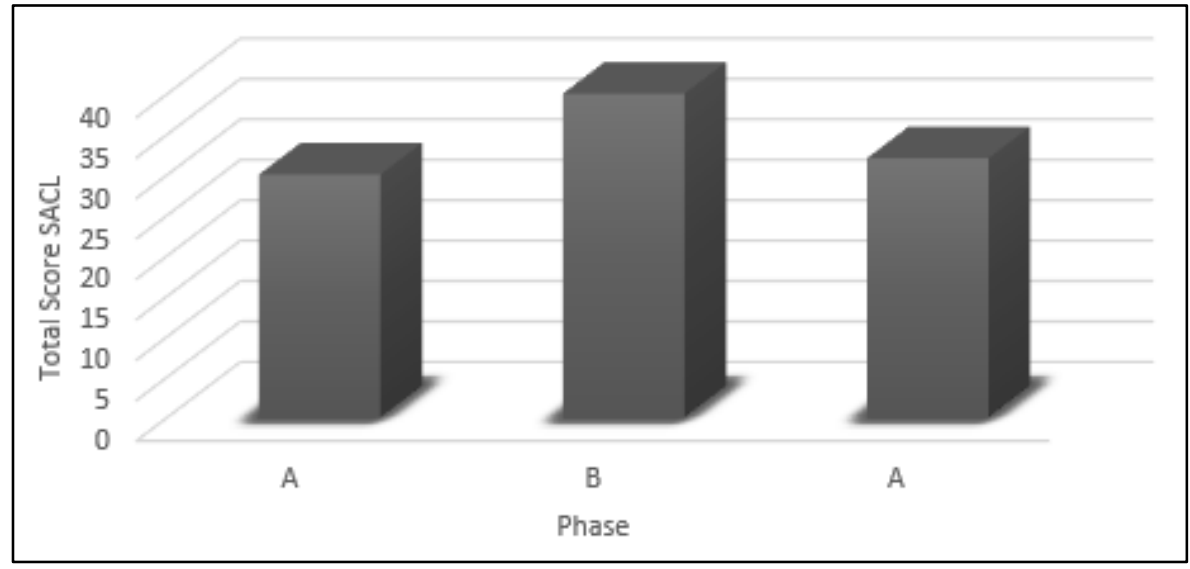

Figure 14. Social Assessment Checklist (SACL) scores per phase for P2. 


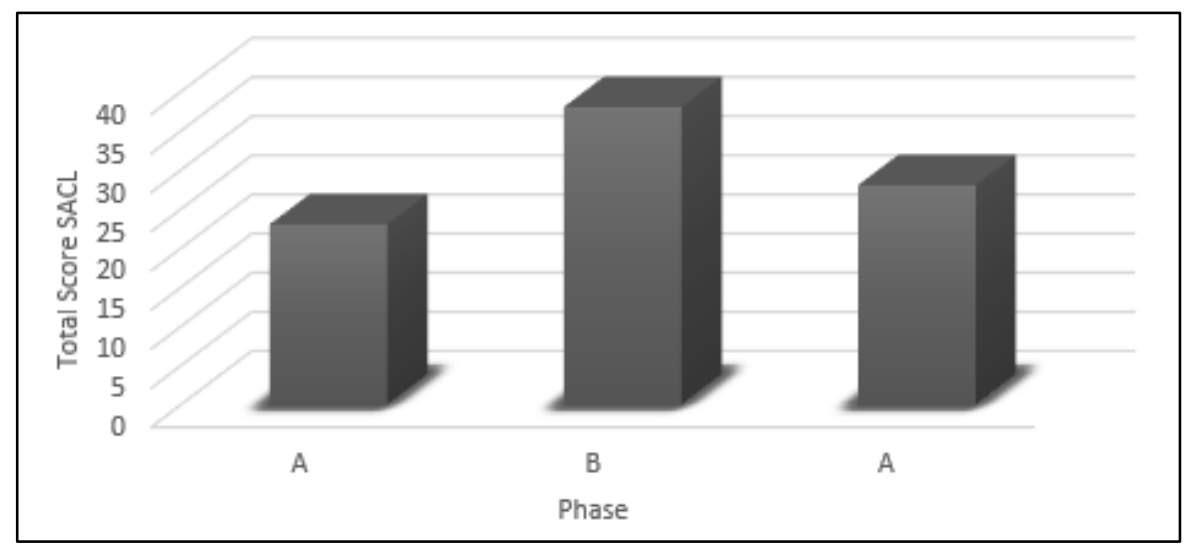

Figure 15. Social Assessment Checklist (SACL) scores per phase for P3.

\section{Mothers' Perceptions of Changes in Speech Intelligibility and Social Interactions}

The third research question was "What are the effects of expressive language stimulation activities using VVAs on the intelligibility of children with ASD, as rated by their mothers?"

To answer this question, the results from the PACL was used. Before engaging in the study, as well as after each phase was completed, mothers were asked to complete the PACL. Figures 16, 17, and 18 present the PACL results for P1, P2, and P3, respectively. As shown in the figures, all the mothers noted improvement in their children's speech intelligibility and social interactions. Additionally, they indicated that they were satisfied with the VVA. Overall, the results suggested that using VVAs had a positive effect on the intelligibility of children with ASD, with mild to minimal parental support.

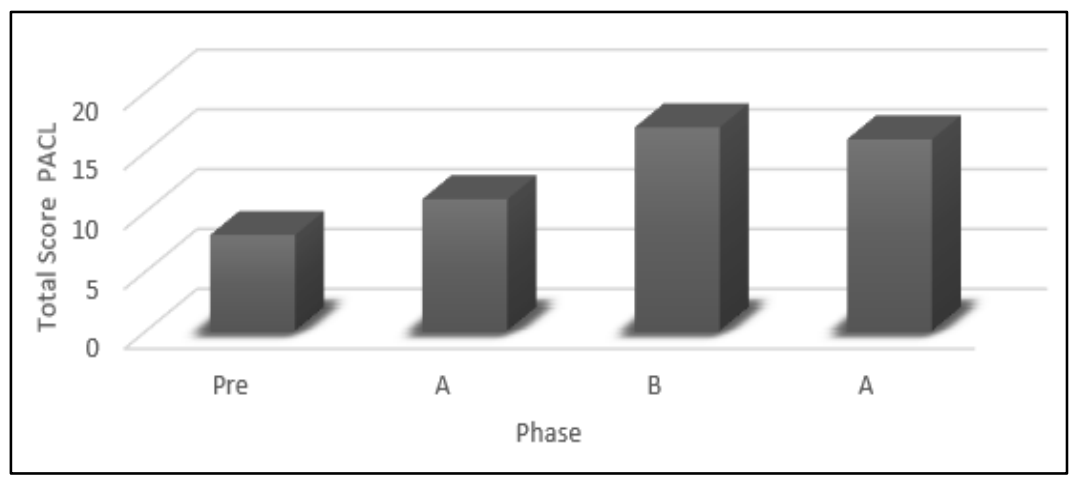

Figure 16. PACL scores per phase for P1. 


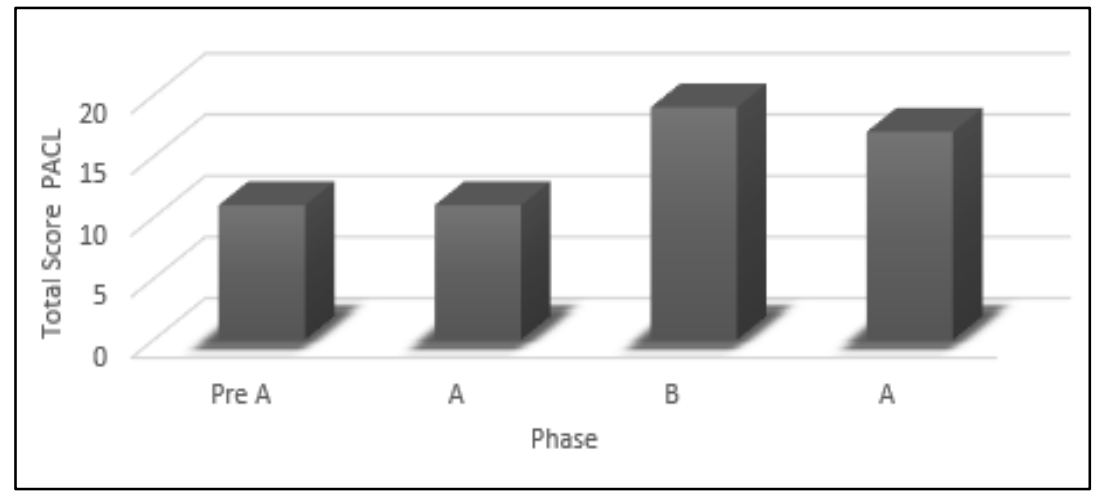

Figure 17. PACL scores per phase for P2.

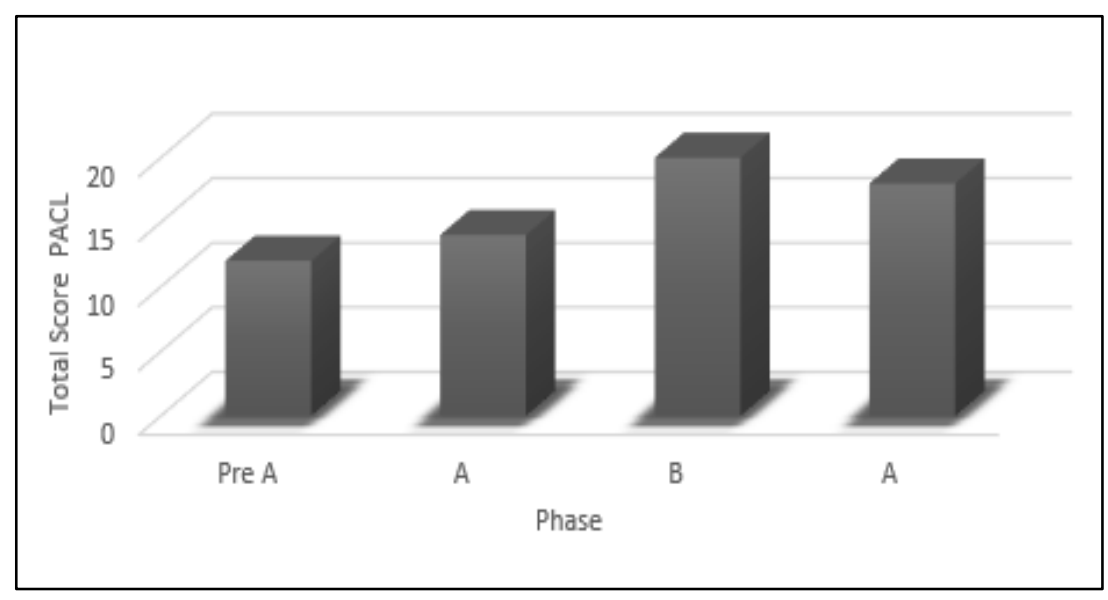

Figure 18. PACL scores per phase for P3.

\section{Discussion}

Children with ASD tend to have communication and social interaction deficits. Their deficiencies in communication mainly come from the difficulties they face regarding language acquisition. Although researchers have demonstrated the significant role artificial intelligence can play in interventions for children with ASD, the role and effectiveness of VVAs has not been satisfactorily examined. Therefore, this study aimed to explore the effectiveness of VVAs for enhancing speech and social interaction skills in children with ASD.

Overall this study's results showed improvements in participants' expressive verbal vocabulary, production of short phrases, and social interactions during the intervention phases compared with a traditional intervention. The participating children were able to interact effectively with the VVA platform and produce new expressive vocabulary. The intervention phase data showed improvement in expressive verbal output and social interactions compared with the traditional baseline data. The children were able to correctly pronounce more words in fewer attempts. Additionally, the children's interactions with their 
siblings were also reported to increase. The mothers reported being satisfied with using this program. These findings suggest that VVA programs might be useful as home-based intervention for children with speech and social difficulties. Sahin et al. [26] reported very similar findings in their study that investigated the use of digital augmented reality in an intervention for social communication, motivation, and cognition in individuals with ASD in a school environment. Further, this study is notable, as it explores the use of a technology that is readily available in home settings. Furthermore, it strengthens suggestions that utilizing VVAs" "humanlike" conversational skills could provide support for developing speech and social interaction skills at home [22,33].

Children with ASD generally have significant challenges in social interactions. Thus, utilizing a tool that could be readily available in their homes and that could potentially improve their social interaction skills could be very beneficial to these children and their families. In studies performed by Ireland et al. [24] and Parson et al. [25], participants showed improvements in their social interactions with the use of avatars and virtual reality applications in a simulated environment. Likewise, the findings of this study supported the effectiveness of using VVAs to enhance the participants' speech and social interaction skills.

Qualitatively, the mothers, who participated in this study, noted multiple advantages of using VVAs. They asserted that Siri captured the children's attention, as they asked their siblings to speak to and play with Siri. Further, the mothers noted that the time the children spent interacting with their siblings increased dramatically while using Siri. They indicated that prior to this, they experienced difficulties in finding activities that would be of interest to their children and could also potentially be beneficial for developing social and language skills. Indeed, these advantages could indirectly benefit children who have difficulties using expressive language, as well as with social interaction. It is also worth noting that one of the participants developed an interest in writing whatever he asked Siri, since the child observed Siri typing whatever was said to it.

Although the results of this study showed that the VVA intervention had positive effects on expressive language and social interaction skills, it is still unclear whether this was entirely due to the VVA. These improvements could be attributable to the mothers' compliance to the intervention and follow-up. However, undoubtedly, the VVAs played some role, because the mothers also noted that their children were more interested in using the VVAs than they were in the traditional (baseline) method of learning new vocabulary and social interaction skills. The participating mothers reported that their children started to imitate the new words they heard from Siri. For example, the mother of P1 described her surprise over her child's improvement and excitingly sent a video to the researcher showing the child saying, "I am not sure I understand," which was identical to a phrase commonly used by Siri. Similarly, the mother of P2 said that her child kept asking Siri questions, such as "Who are you?" and "How old are you?" P3 showed less interest in saying new words and more interest in asking Siri to open his favorite game. Nevertheless, this can be considered a positive interaction. Previous research suggested that distraction-free, non-judgmental conversation could be why children with ASD find it appealing to interact with smart interactive platforms similar to VVAs, and the present study also supports such a supposition [34,35].

One important advantage of using a single-subject design in autism studies is that it allows the use of a small sample size while focusing on rich, in-depth data collection, as well as tracking participants' individual progress. Such an experimental design is advantageous in ASD interventional studies, because ASD is heterogenous, with a wide range of 
characteristics; thus, generalizations are usually difficult to make. Further, these experimental interventions can be customized according to the needs and goals of each participant, while each participant's pre-study performance can act as their own baseline.

\section{Study Limitations and Implications}

Several limitations can be identified in this study. First, it was a single-subject design study with a low number of participants, thus limiting the generalizability of the findings. The second is the use of the A-B-A single-subject design because of time constraints. To further develop the findings on the effectiveness of VVA use for children with ASD, an A-B-A-B design might be stronger, because it would provide another opportunity to evaluate the effects of the intervention phase on the target skills or behaviors for the second withdrawal phase. The third limitation is the small number of sessions per phase. Increasing the number of sessions for each phase could also help more accurately determine the intervention's effectiveness.

\section{Directions for Future Research}

In addition to considering how to overcome the aforementioned limitation in future studies, the following constructive suggestions can be made. The first is to extend the range of the target population to include not only children with ASD but also all children with speech and social difficulties. The second is to measure the impact of mothers' intervention as compared to regular therapy sessions provided by therapists or special education teachers using validated objective and subjective assessment tools.

Despite its limitations, the findings of this study could contribute to providing assistance to children with speech and social difficulties, such as ASD, by using artificial intelligence platforms, such as VVAs, in homes and schools.

\section{Conclusions}

In conclusion, this study's results demonstrated that using VVA had positive influence on on expressive verbal vocabulary, production of short phrases, and social interactions in 3 children who have expressive language difficulty as well as social interaction difficulty due to ASD. The participated children were able to interact effectively with the VVA platform and produce new expressive vocabulary. The children were able to correctly pronounce more words in fewer attempts. Additionally, this study strengthens the idea that utilizing VVAs' "humanlike" conversational skills may provide support for the development of speech and social interaction skills at home for children with ASD . 


\section{Data Availability}

The datasets used during the current study are available from the corresponding author on reasonable request.

\section{Ethical Approval}

This study was approved by the Medical Ethics Committee of Zhejiang Xiaoshan Hospital.

\section{Consent}

Informed consent was obtained from parents or guardians of all children.

\section{Conflicts of Interest}

All authors declare no conflict of interests.

\section{Funding Statement}

No funding was obtained for this study.

\section{Authorship Statement}

All the authors participated in the design, conduct and completion of the research as well as approve this manuscript and agree with this submission.

\section{Authors' contributions}

Dr. Mohammed Safi and Ms. Badriya Al Sadrani designed the study. Ms. Badriya Al Sadrani and Dr. Mohammed Safi conducted the study, including participants recruitment, data collection, and data analysis. Dr. Mohammed Safi, Ms. Badriya Al Sadrani prepared the manuscript draft with important intellectual input from Ashraf Mustafa. Dr. Mohammed Safi and Ms. Badriya Al Sadrani performed the data analysis with input from Mr Ashraf Mustafa. The UAEU provided funding for editorial support. All authors approved the final manuscript. 


\section{References}

1. Patel, V. B., Preedy, V. R., \& Martin, C. R. Comprehensive guide to autism. New York (NY): Springer Reference; 2014.

2. Mata, L., Panasoara, G., Fatet, S., et al. Systematic review of technology-based psychoeducational interventions for language disorders. Broad Research in Artificial Intelligence and Neuroscience. 2018;9(1):151-162.

3. Thabtah, F. Machine learning in autistic spectrum disorder behavioral research: A review and ways forward. Informatics for Health and Social Care. 2018;44(3):278297.

4. Porayska-Pomsta, K., Keay-Bright, W., Kossyvaki, L., et al. Blending human and artificial intelligence to support autistic children's social communication skills. ACM Transactions on Computer-Human Interaction. 2018;25(6):1-35.

5. Boucenna, S., Narzisi, A., Tilmont, E., et al. Interactive technologies for autistic children: A review. Cognitive Computation. 2014;6(4):722-740.

6. Esteban, P. G., Baxter, P., Belpaeme, T., et al. How to build a supervised autonomous system for robot-enhanced therapy for children with autism spectrum disorder. Paladyn, Journal of Behavioral Robotics. 2017;8(1):18-38.

7. Jaliaawala, M. S. \& Khan, R. A. Can autism be catered with artificial intelligenceassisted intervention technology? A comprehensive survey. Artificial Intelligence Review. 2019;53:1039-1069.

8. Baird, Gillian, et al. "Prevalence of disorders of the autism spectrum in a population cohort of children in South Thames: the Special Needs and Autism Project (SNAP)." The lancet 368.9531 (2006): 210-215.

9. American Psychiatric Association. Diagnostic and statistical manual of mental disorders (DSM-5®). American Psychiatric Pub, 2013.

10. Kamp-Becker, Inge, et al. "Health-related quality of life in adolescents and young adults with high functioning autism-spectrum disorder." GMS Psycho-Social-Medicine 7 (2010).

11. Koegel, Lynn Kern, et al. "The importance of early identification and intervention for children with or at risk for autism spectrum disorders." International journal of speech-language pathology 16.1 (2014): 50-56.

12. CENTERS FOR DISEASE CONTROL AND PREVENTION (CDC). "Have identified possible red flags for autism spectrum disorder in young children." (2019).

13. Eapen, Valsamma, et al. "Screening for Autism Spectrum Disorders using the PEDS and MCHAT." Journal of Mental Health Research in Intellectual Disabilities 7.1 (2014): 1-13. 
14. Boucher, Jill. "Putting theory of mind in its place: psychological explanations of the socioemotional-communicative impairments in autistic spectrum disorder." Autism 16.3 (2012): 226-246.

15. Tager-Flusberg, Helen. "Understanding the language and communicative impairments in autism." International review of research in mental retardation. Vol. 23. Academic Press, 2000. 185-205.

16. Fay, W., and A. Schuler. "Emerging language in children with autism." (1980).

17. McGregor, Karla K. "21 Studying Children with Language Impairment." Research Methods in Child (2012): 317.

18. Tek, Saime, et al. "Do children with autism spectrum disorders show a shape bias in word learning?." Autism Research 1.4 (2008): 208-222.

19. Norbury, Courtenay Frazier, Helen Griffiths, and Kate Nation. "Sound before meaning: Word learning in autistic disorders." Neuropsychologia 48.14 (2010): 4012-4019.

20. Kalandadze, T., Norbury, C., Nærland, T., \& Næss, K. B. Figurative language comprehension in individuals with autism spectrum disorder: A meta-analytic review. Autism. 2016;22(2):99-117.

21. Haebig, E., Saffran, J. R., Ellis Weismer, S. Statistical word learning in children with autism spectrum disorder and specific language impairment. Journal of Child Psychology and Psychiatry. 2017;58(11):1251-1263.

22. Hoy, M. B. Alexa, Siri, Cortana, and more: An introduction to voice assistants. Medical Reference Services Quarterly. 2018;37(1):81-88.

23. Shin, S., Min, B., Rayz, J., \& Matson, E. T. Semantic knowledge-based language education device for children with developmental disabilities. 2017 First IEEE International Conference on Robotic Computing (IRC). 2017 April 10-12; Taichung, Taiwan; IEEE; 2017;340-345.

24. Ireland, D., Bradford, D., Farr-Wharton, G. Social fringe dwellers: Can chat-bots combat bullies to improve participation for children with autism? The Journal of Community Informatics. 2018;14(1):105-119.

25. Parsons, S., Leonard, A., Mitchell, P. Virtual environments for social skills training: Comments from two adolescents with autistic spectrum disorder. Computers \& Education, 2006;47(2):186-206.

26. Sahin, N. T., Abdus-Sabur, R., Keshav, N. U., et al. Case study of a digital augmented reality intervention for autism in school classrooms: Associated with improved social communication, cognition, and motivation via educator and parent assessment. Frontiers in Education. 2018;3:1-13. 
27. Chen, C., Lee, I., \& Lin, L. Augmented reality-based video-modeling storybook of nonverbal facial cues for children with autism spectrum disorder to improve their perceptions and judgments of facial expressions and emotions. Computers in Human Behavior. 2016;55:477-485.

28. Zirpoli, T. J. Behavior management: Positive applications for teachers. Boston: Pearson; 2016.

29. Lobo, M. A., Moeyaert, M., Cunha, A. B., et al. Single-case design, analysis, and quality assessment for intervention research. Journal of Neurologic Physical Therapy. 2017:41(3):187-197.

30. Shaughnessy, J. J., Zechmeister, E. B., Zechmeister, J. S. Research methods in psychology. Dubuque: McGraw-Hill Education; 2015.

31. Gilliam, James E. "GARS-3: Gilliam Autism Rating Scale-Third Edition." (2013).

32. Fraenkel, J. R., Wallen, N. E., Hyun, H. H. How to design and evaluate research in education. New York: McGraw-Hill Education; 2019.

33. Porcheron, M., Fischer, J. E., Mcgregor, M., et al. Talking with conversational agents in collaborative action. In: Companion of the 2017 ACM Conference on computer supported cooperative work and social computing - CSCW 17 Companion. New York (NY), USA; 2017;431-436.

34. Robins, B., Dautenhahn, K., Wood, L., et al. Developing interaction scenarios with a humanoid robot to encourage visual perspective taking skills in children with autism Preliminary proof of concept tests. In: Kheddar A. et al. (Eds) Social robotics. ICSR 2017. Lecture Notes in Computer Science, Springer, Cham. 2017;10652:147-155.

35. Wood, L., Dautenhahn, K., Robins, B., et al. Developing child-robot interaction scenarios with a humanoid robot to assist children with autism in developing visual perspective taking skills. In: 2017 26th IEEE International Symposium on Robot and Human Interactive Communication (RO-MAN). Lisbon, Portugal: IEEE; 2017;10551060. 
Appendix A. Parent's Assessment Checklist.

\section{Parent's Assessment Checklist (PACL)}

1. On average, I understand about ----- \% of my child's speech when he talks to me:
$0-30 \%$
$40-50 \%$
$60-70 \%$
$80-90 \%$

2. My other children/ family member ------- understand my child ( ) speech when he talks to them:
Fully
often
somewhat
rarely

3. The average interaction of my child with his siblings is

Frequently Occasionally neutral rarely

4. On average, the Virtual Voice Assistant (VVA) replayed -----\% accurately to my child speech.
$0-30 \%$
$40-50 \%$
$60-70 \%$
$80-90 \%$

5. My satisfaction in using the VVA to improve my child speech and social interaction is:
Very satisfied
Satisfied
dissatisfied
very dissatisfied 
Appendix B. Social Assessment Checklist.

Social Assessment Checklist (SACL)

Student's initials:

Age:

Gender: Male

Grade:

\begin{tabular}{|c|c|c|c|c|c|c|}
\hline & & $\begin{array}{c}\text { Strongly } \\
\text { Agree }\end{array}$ & Agree & Neutral & Disagree & \begin{tabular}{|l|} 
Strongly \\
Disagree \\
\end{tabular} \\
\hline & Score & 5 & 4 & 3 & 3 & 1 \\
\hline 1. & $\begin{array}{l}\text { Try to get the mother's } \\
\text { attention by saying new } \\
\text { words. }\end{array}$ & & & & & \\
\hline 2. & $\begin{array}{l}\text { Imitate mother words } \\
\text { when interacting with the } \\
\text { VVA }\end{array}$ & & & & & \\
\hline 3. & $\begin{array}{l}\text { Looking at his } \\
\text { mother/sibling when } \\
\text { articulate words correctly }\end{array}$ & & & & & \\
\hline 4. & $\begin{array}{l}\text { Smile/ show happiness } \\
\text { when the VVA does what } \\
\text { the child said. }\end{array}$ & & & & & \\
\hline 5. & $\begin{array}{l}\text { Smile back when his } \\
\text { mother/sibling smile } \\
\text { during interaction with the } \\
\text { VVA }\end{array}$ & & & & & \\
\hline 6. & $\begin{array}{l}\text { Did not mind when his } \\
\text { sibling joins the VVA } \\
\text { session }\end{array}$ & & & & & \\
\hline 7. & $\begin{array}{l}\text { Look at his sibling } \\
\text { reaction/interaction to the } \\
\text { VVA }\end{array}$ & & & & & \\
\hline 8. & $\begin{array}{l}\text { Ask his brother/sister to } \\
\text { take a turn in talking with } \\
\text { the VVA }\end{array}$ & & & & & \\
\hline 9. & $\begin{array}{l}\text { Imitate brother/sister } \\
\text { interaction with the VVA }\end{array}$ & & & & & \\
\hline 10. & $\begin{array}{l}\text { Interact back and forth for } \\
\text { five minutes or more with } \\
\text { his sibling during and after } \\
\text { the session }\end{array}$ & & & & & \\
\hline & Total & & & & & \\
\hline
\end{tabular}


Figures

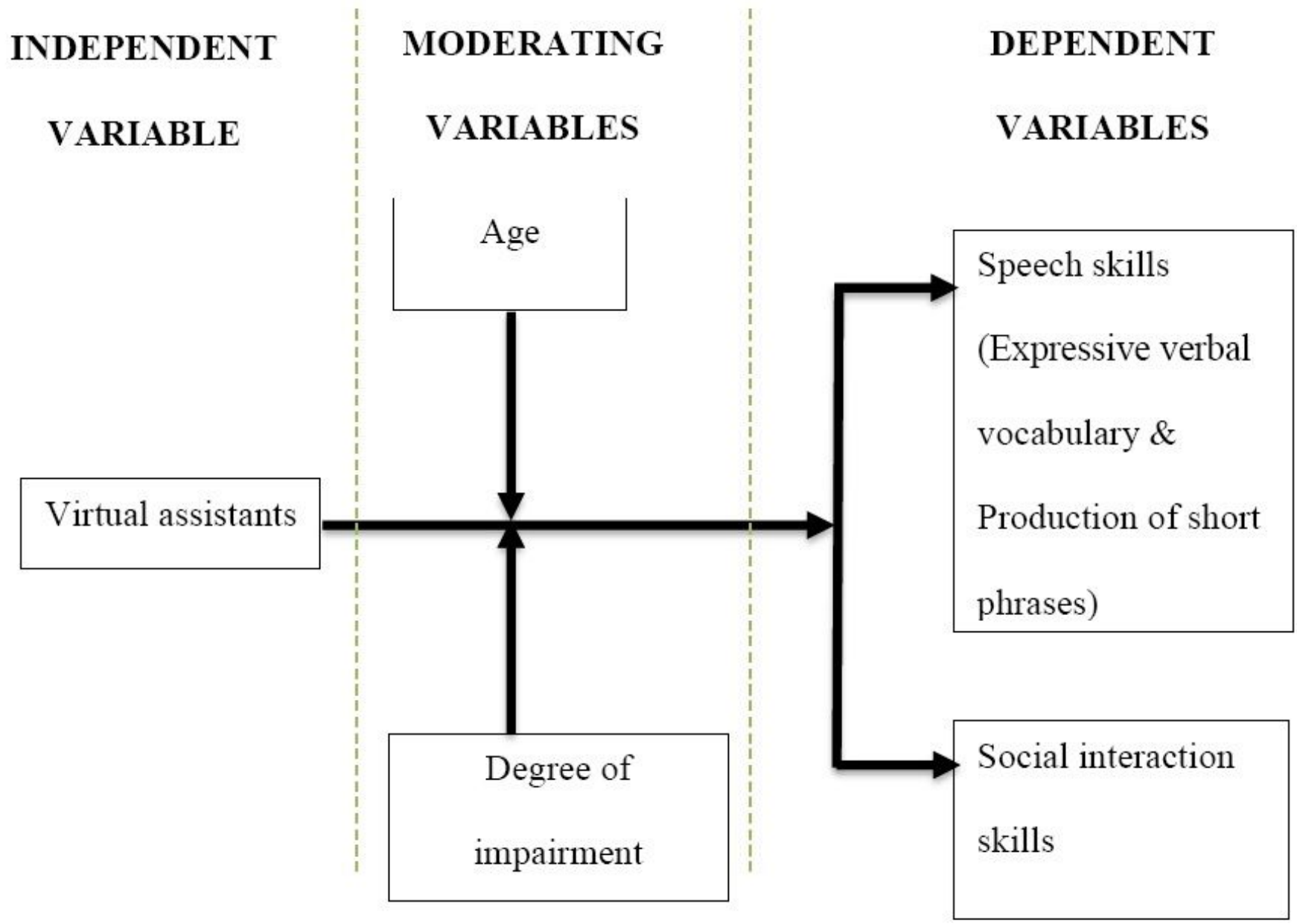

Figure 1

The study's conceptual framework. 


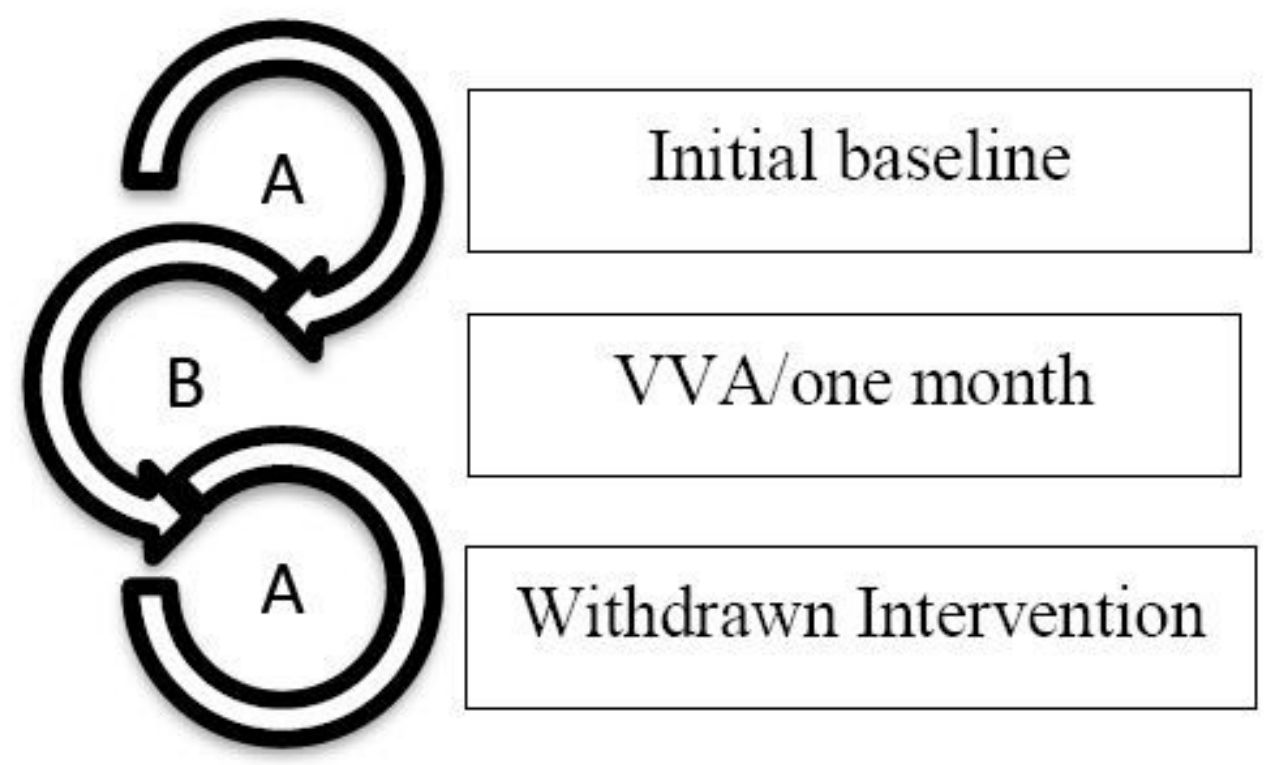

Figure 2

Illustration of the intervention's A-B-A design.

\section{The child: "Siri"}

Siri: "go ahead"

The child or the mother: "hello"

Siri: "hi"

The child or the mother: "car"

Siri: "are looking for a specific car?"

Etc.

\section{Figure 3}

A sample interaction with Siri. 


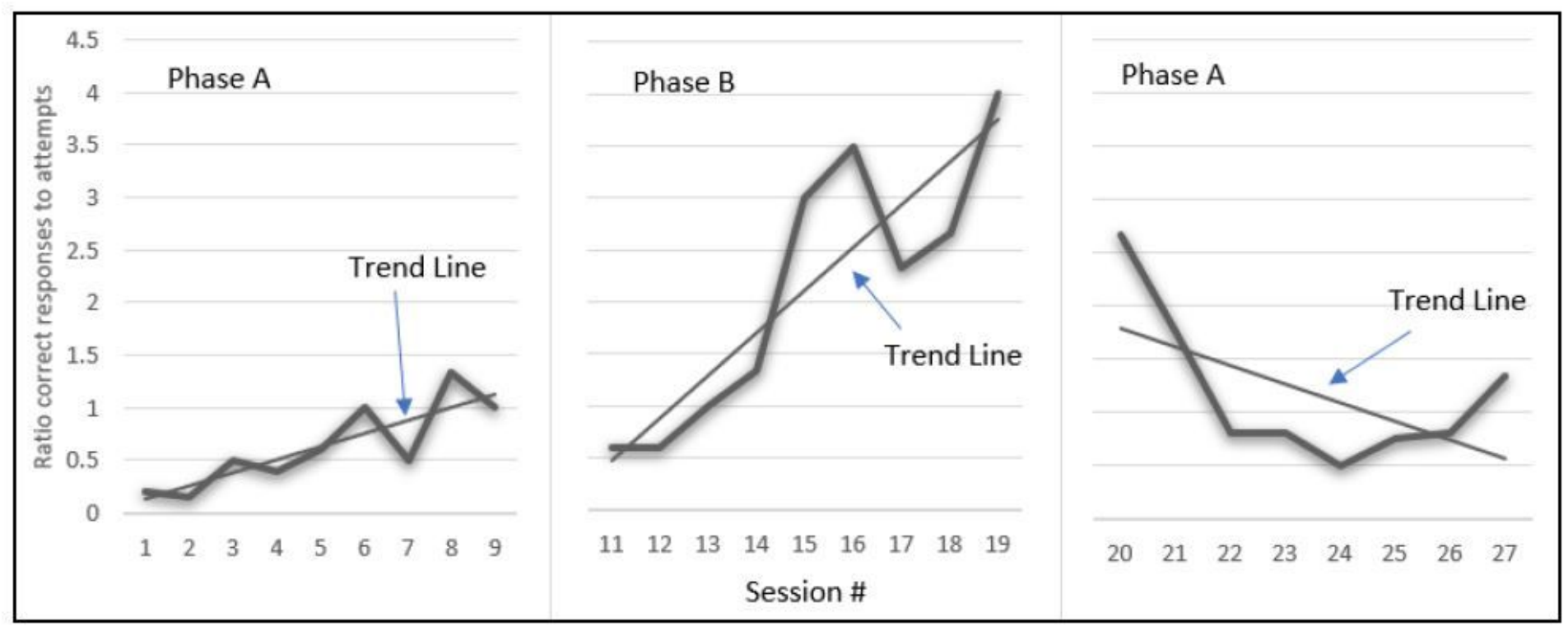

Figure 4

Change in number of correct words produced in relation to attempts per sessions for P1 (1st set of words).

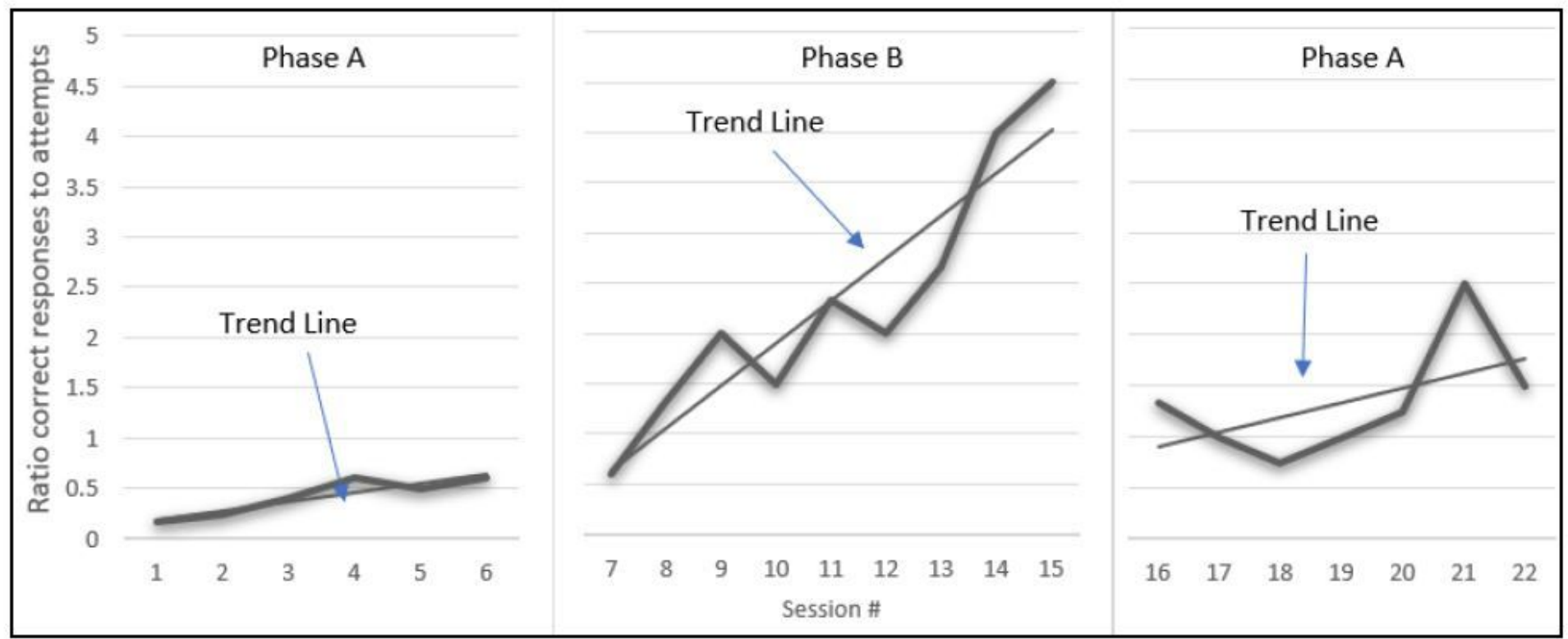

Figure 5

Change in number of correct words produced in relation to attempts per sessions for P1 (2nd set of words). 


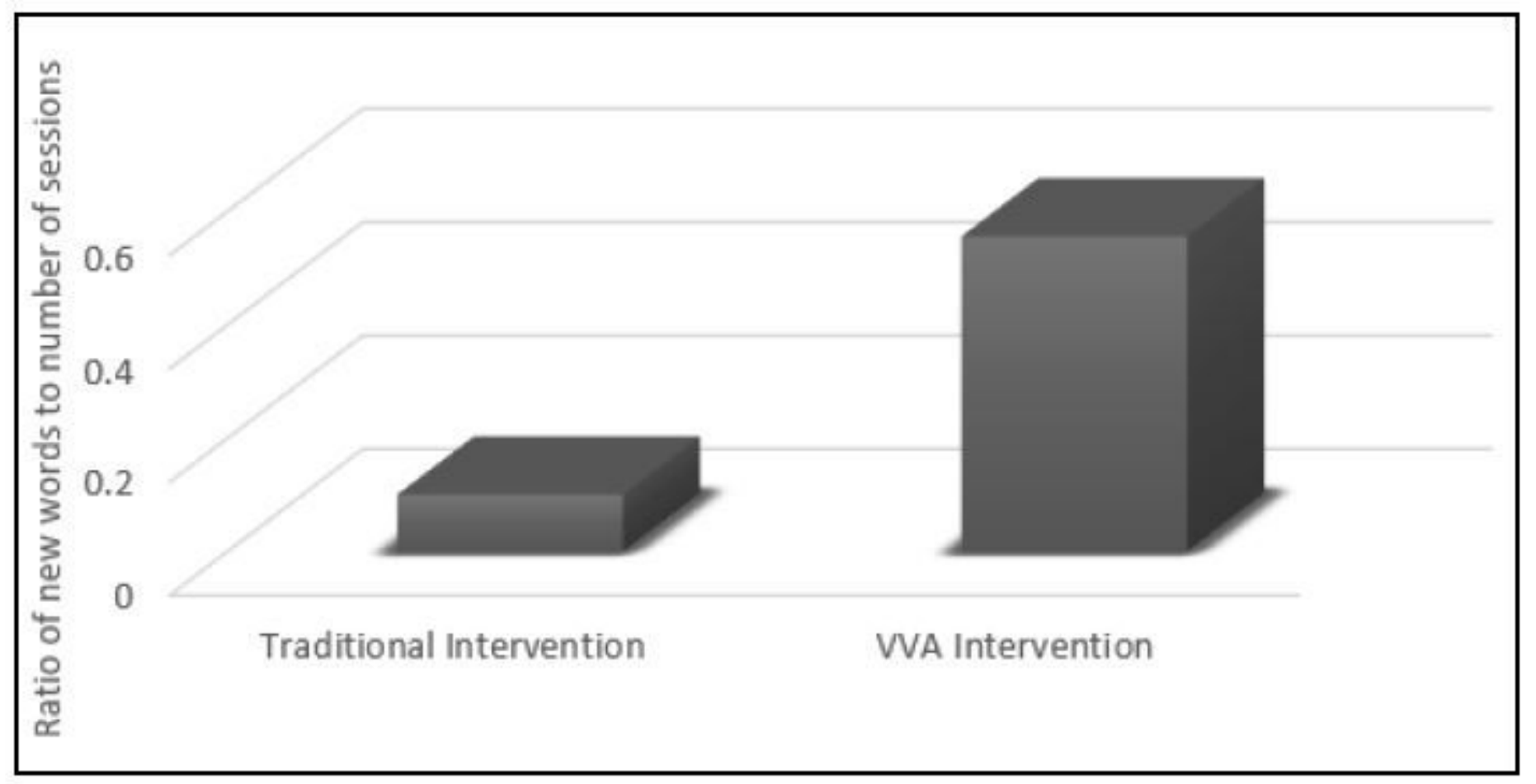

\section{Figure 6}

Comparing the ratio of new words produced to number of sessions between the traditional intervention and VVA intervention for P1.

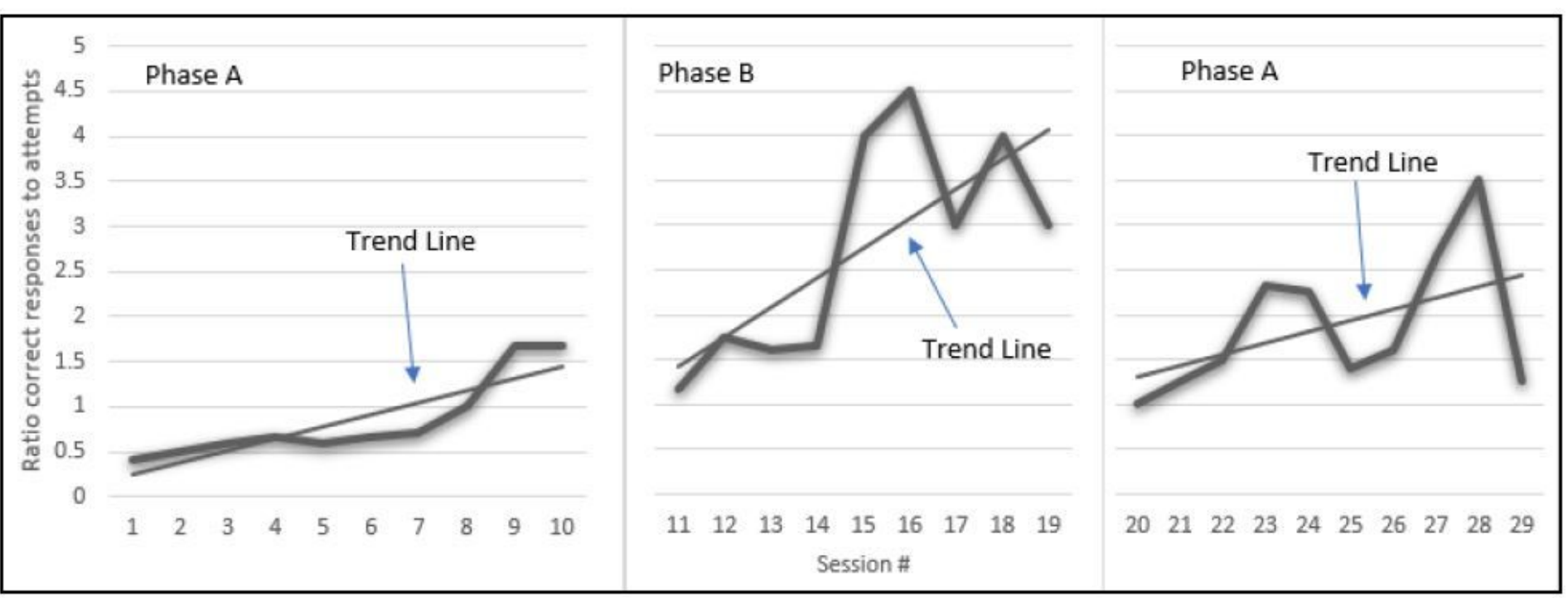

\section{Figure 7}

Change in number of correct words produced in relation to attempts per sessions for P2 (1st set of words). 


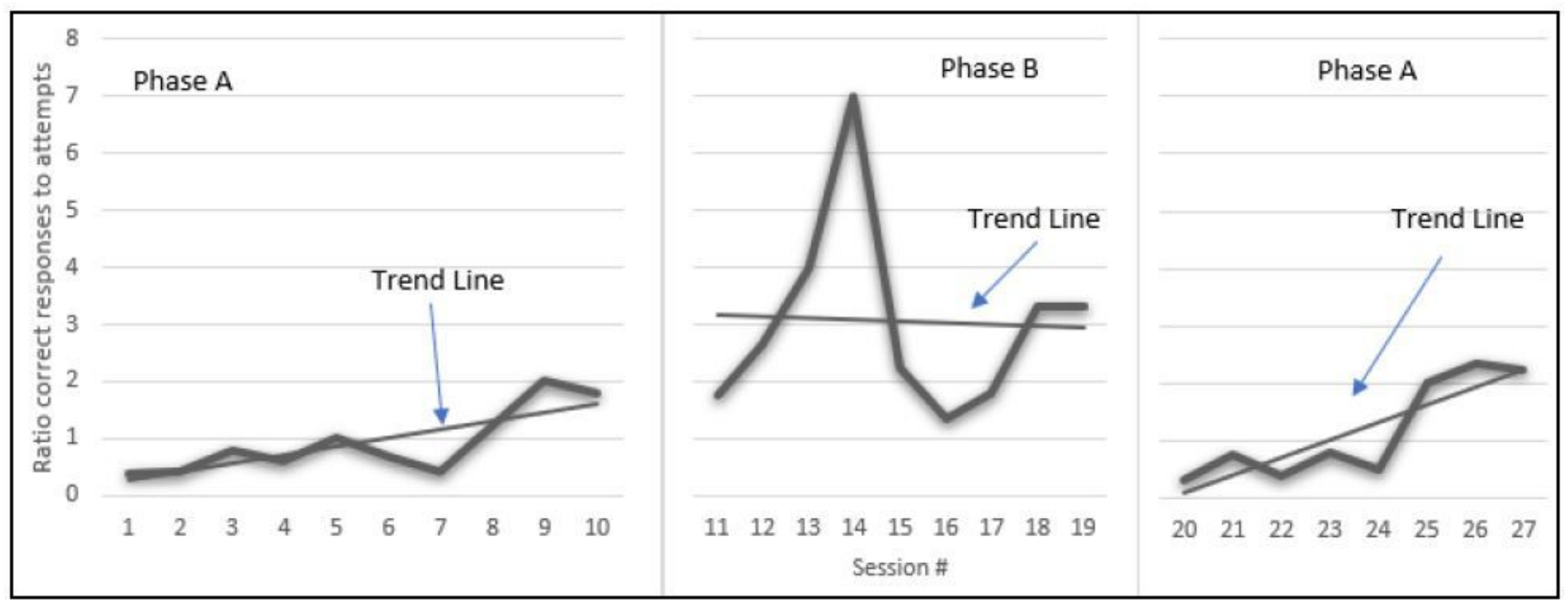

\section{Figure 8}

Change in number of correct words produced in relation to attempts per sessions for P2 (2nd set of words).

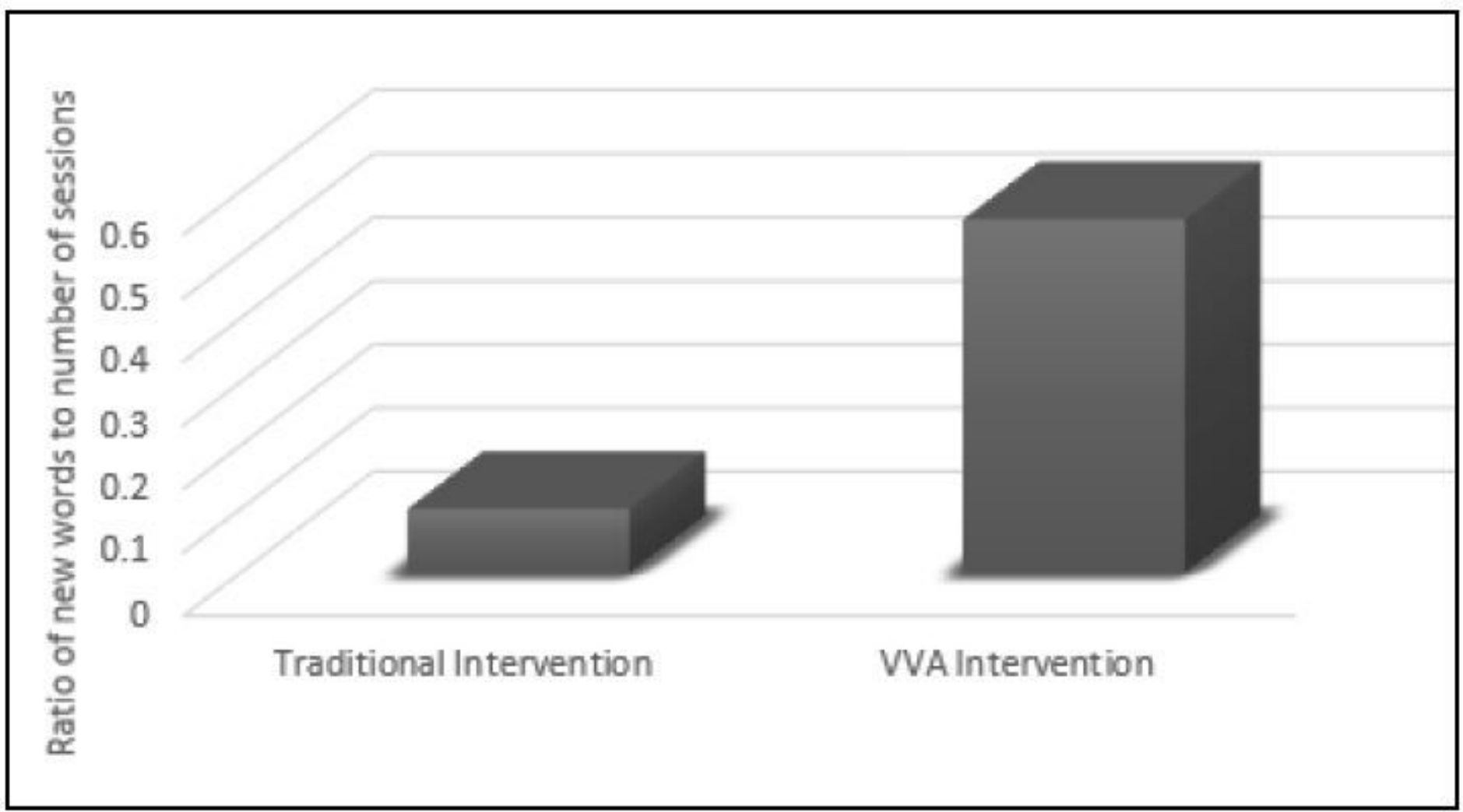

Figure 9

Comparing the ratio of new words produced to number of sessions between the traditional intervention and VVA intervention for $\mathrm{P} 2$. 


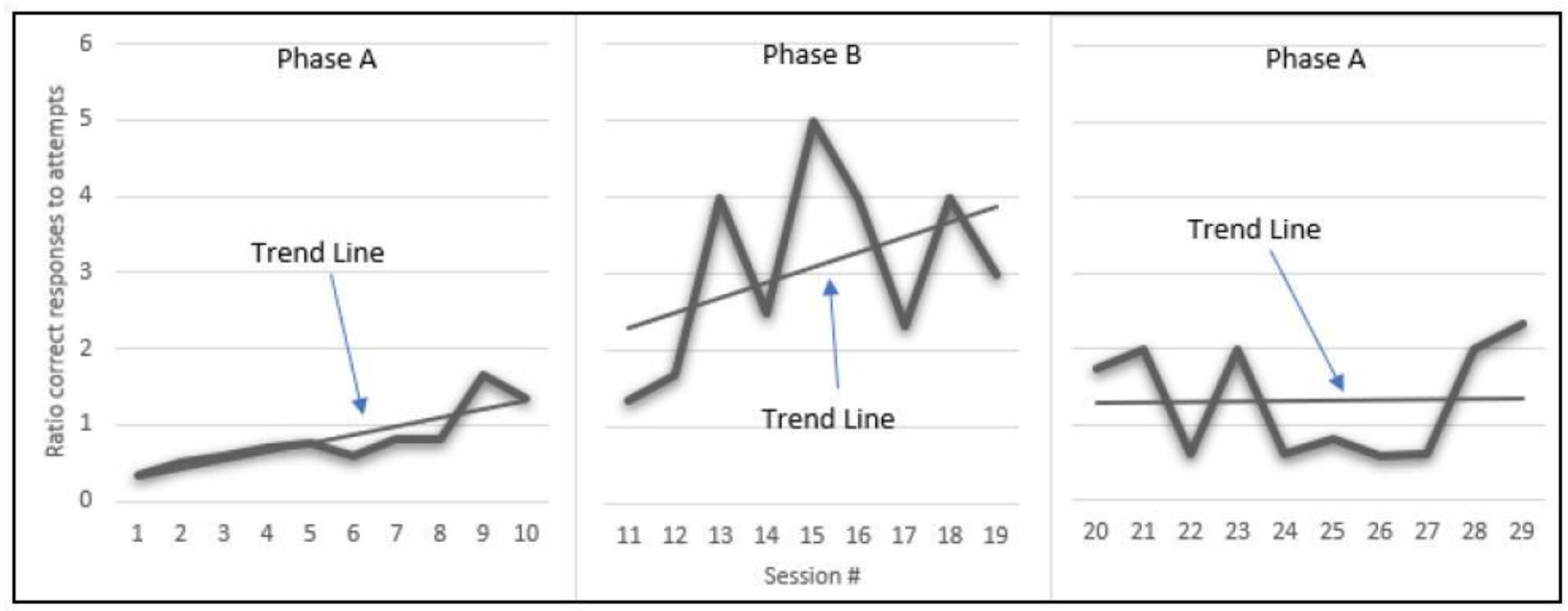

Figure 10

Change in number of correct words produced in relation to attempts per sessions for P3 (1st set of words).

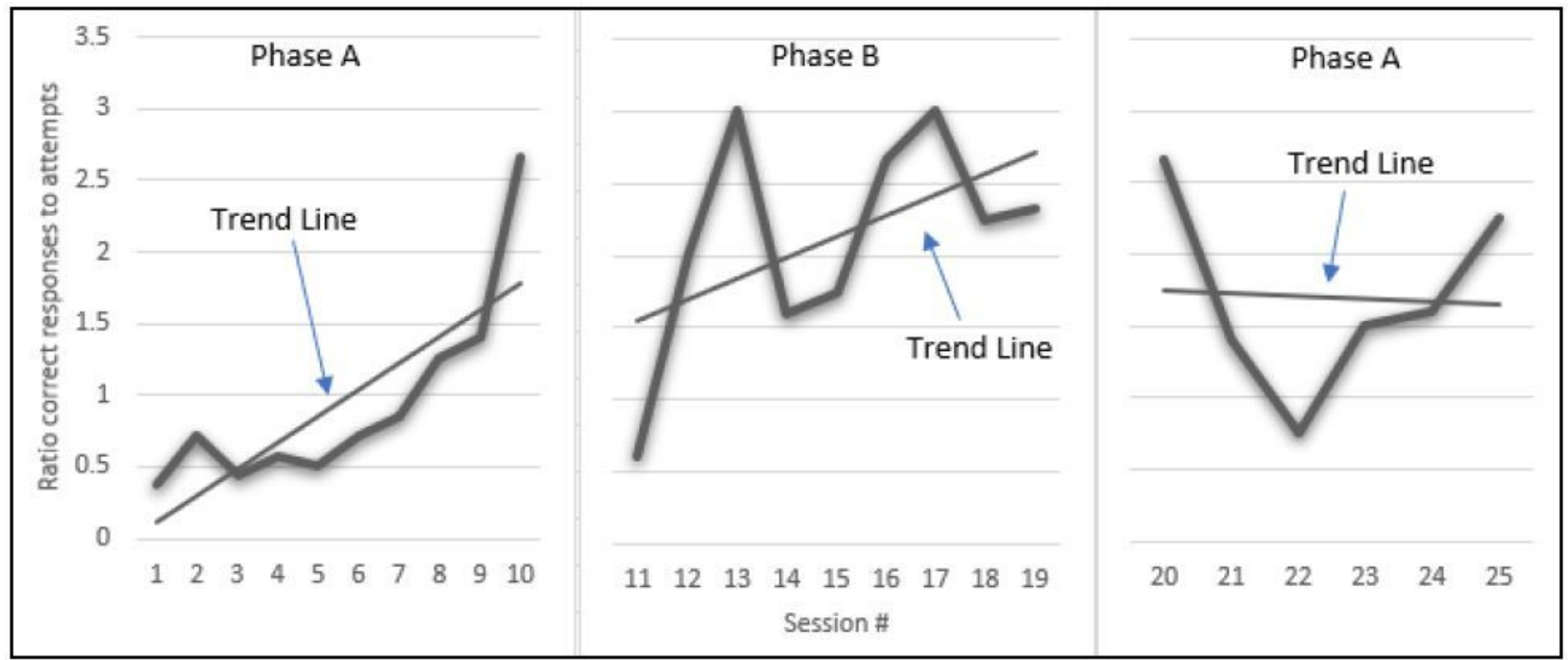

Figure 11

Change in number of correct words produced in relation to attempts per sessions for P3 (2nd set of words). 


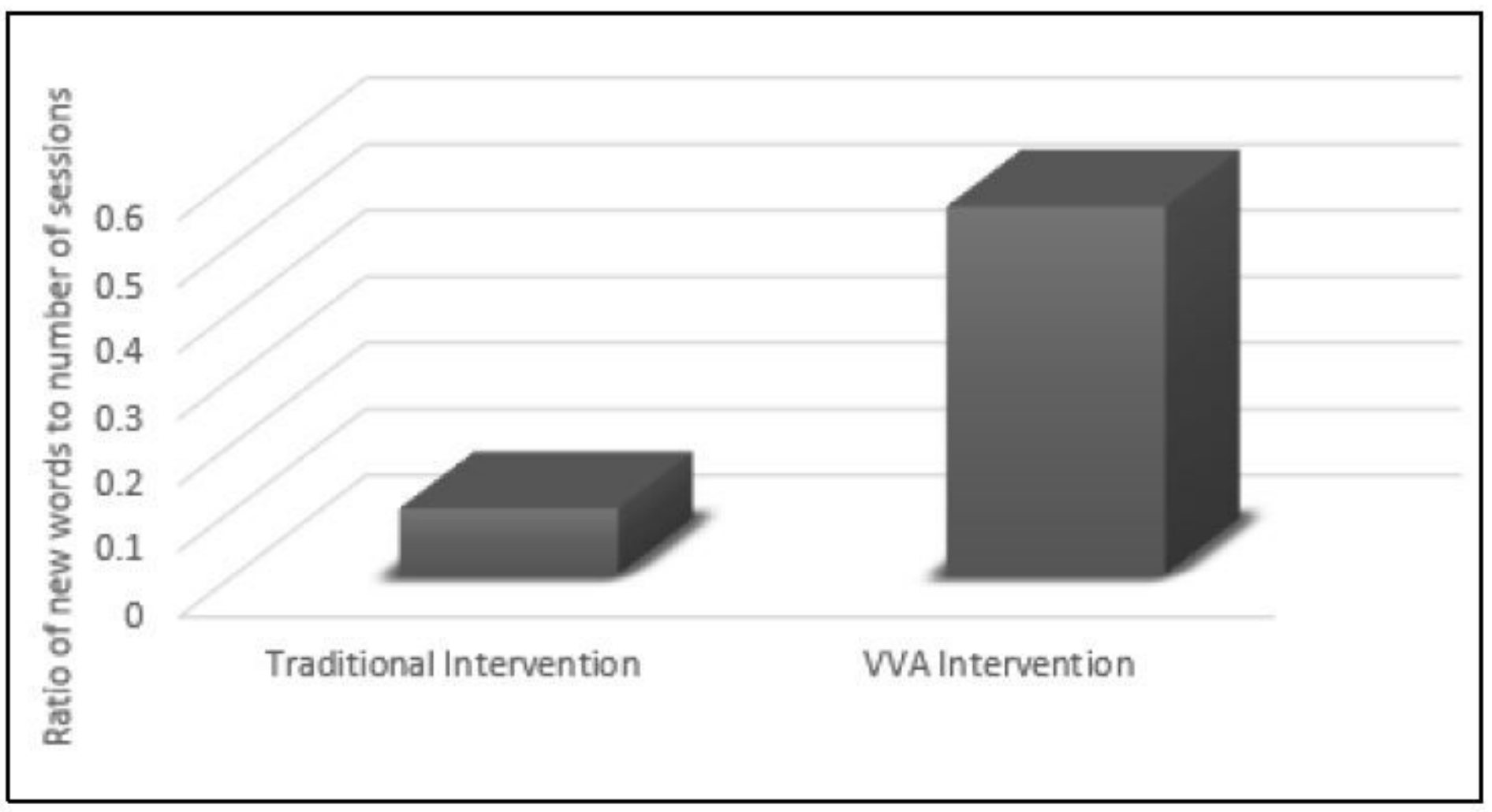

Figure 12

Comparing the ratio of new words produced to number of sessions between the traditional intervention and VVA intervention for P3.

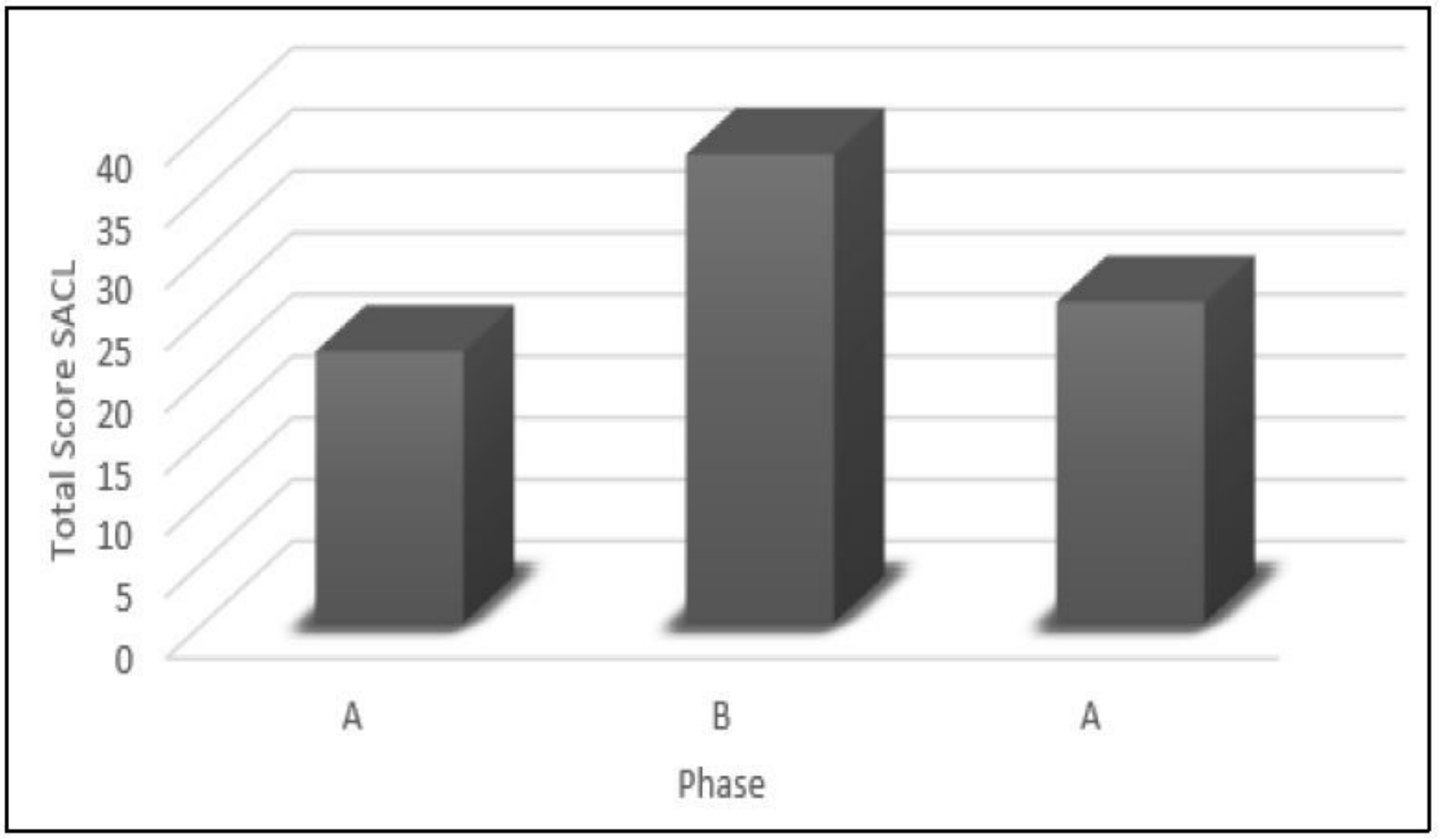


Figure 13

Social Assessment Checklist (SACL) scores per phase for P1.

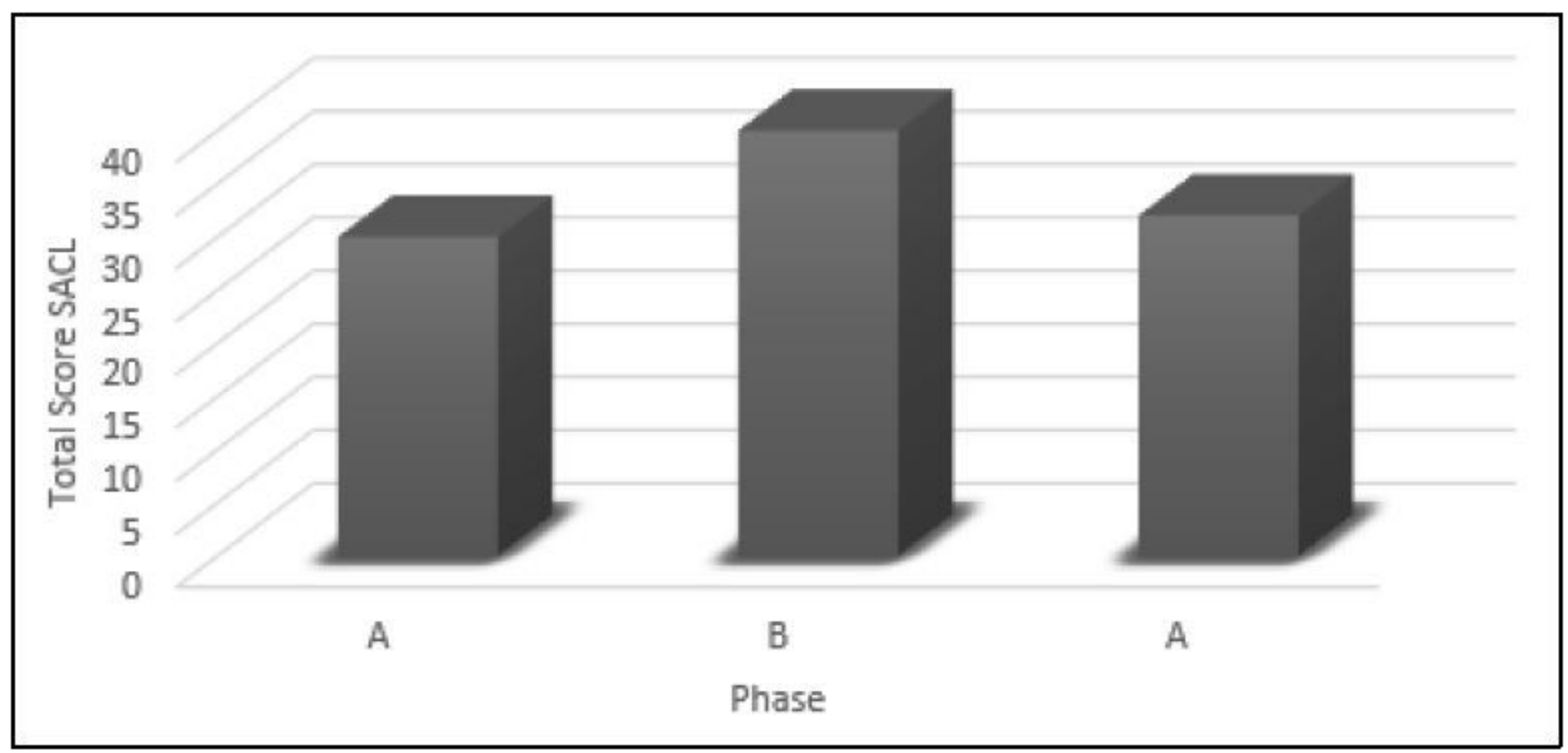

Figure 14

Social Assessment Checklist (SACL) scores per phase for P2.

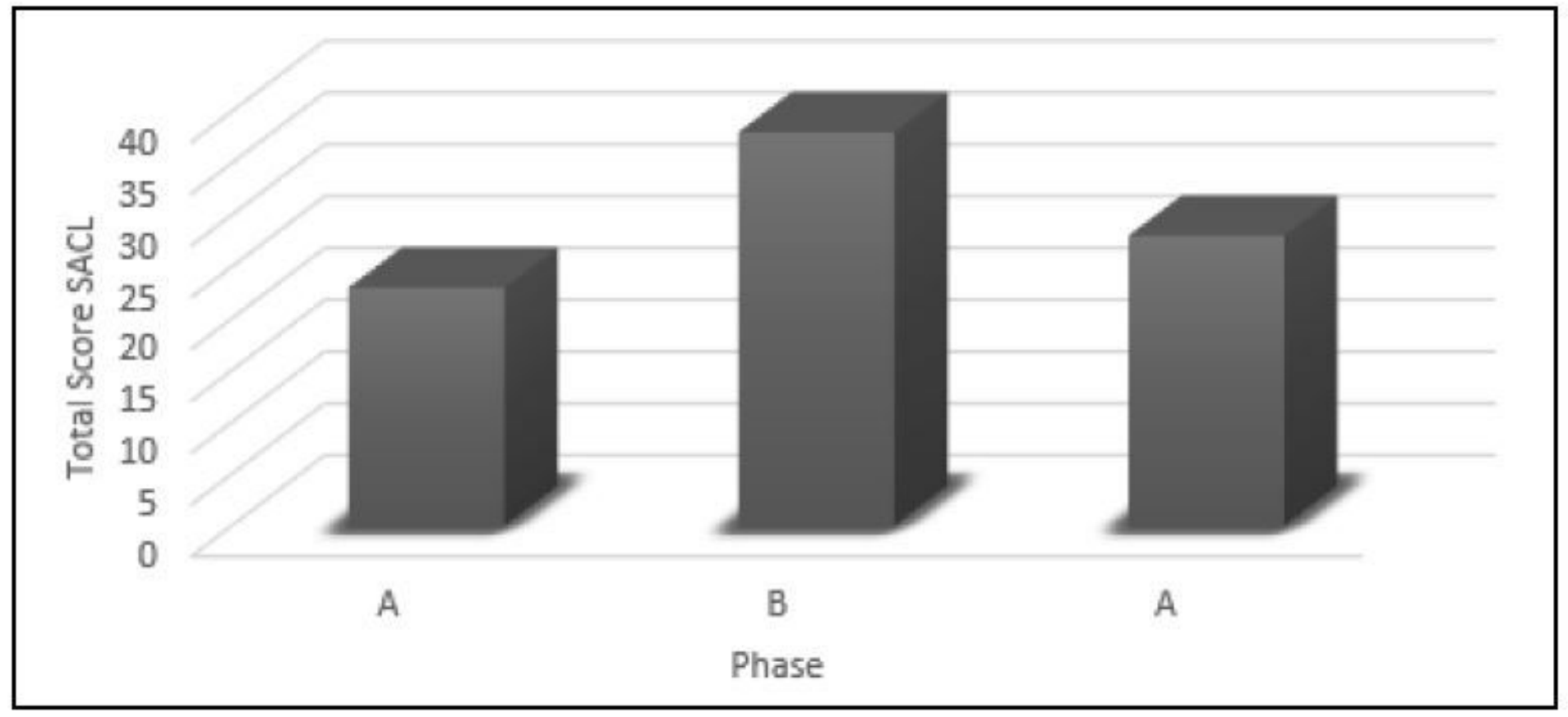

Figure 15

Social Assessment Checklist (SACL) scores per phase for P3. 


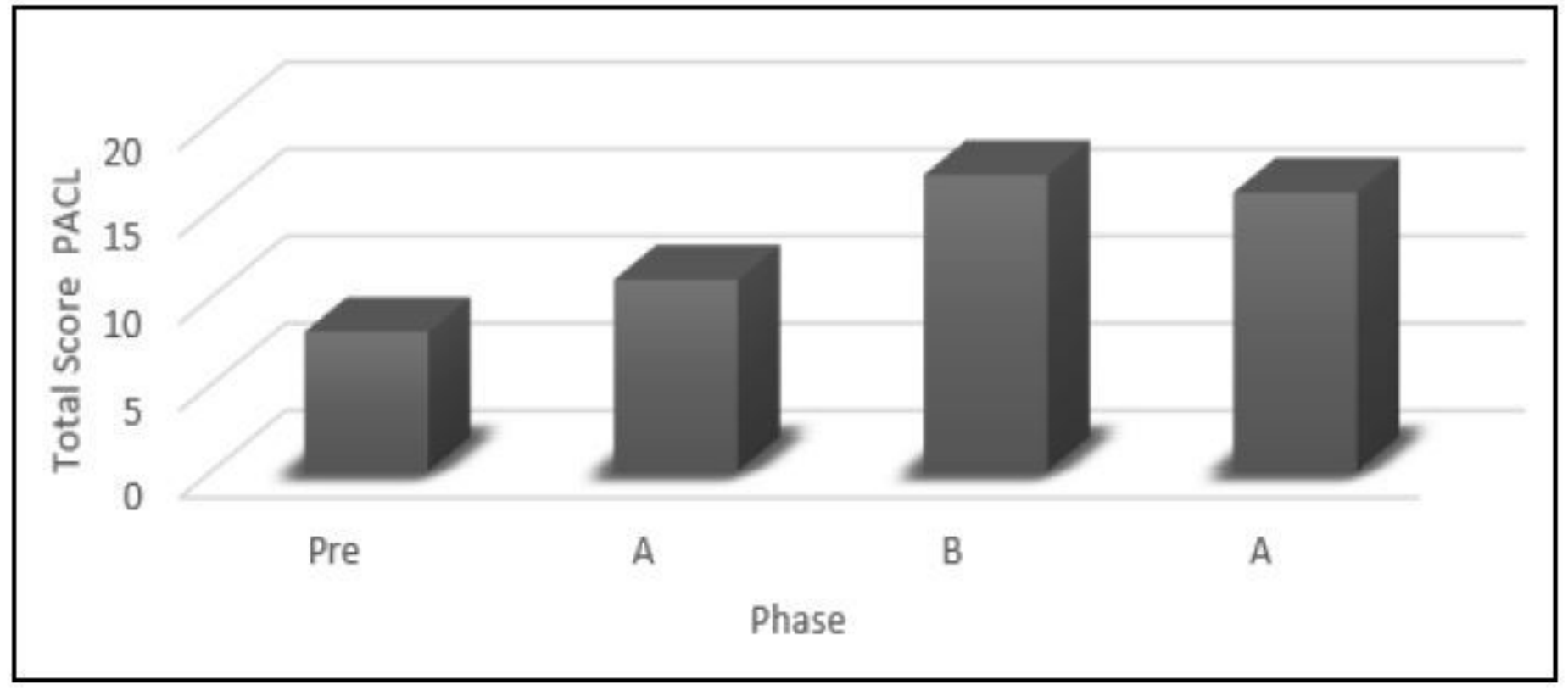

Figure 16

PACL scores per phase for P1.

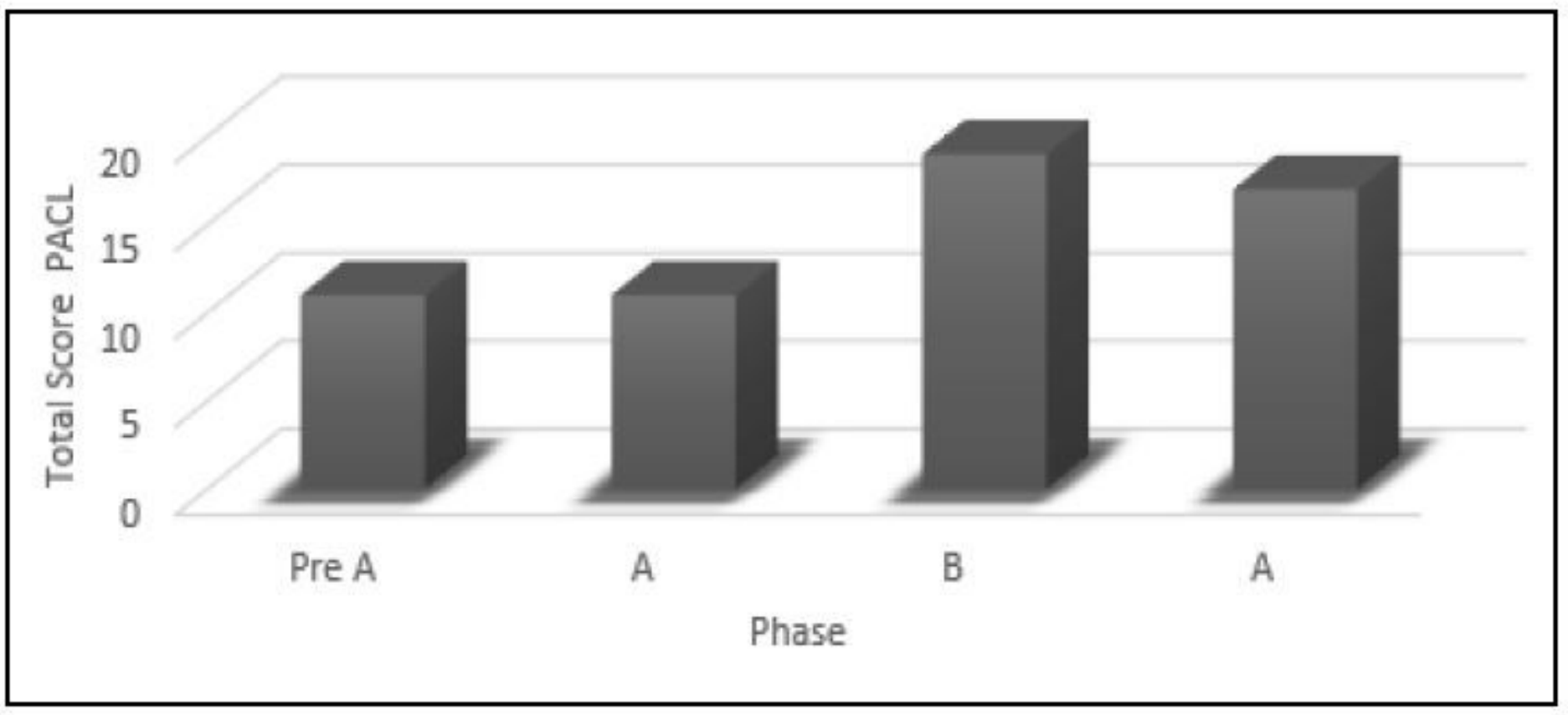

Figure 17

PACL scores per phase for P2. 


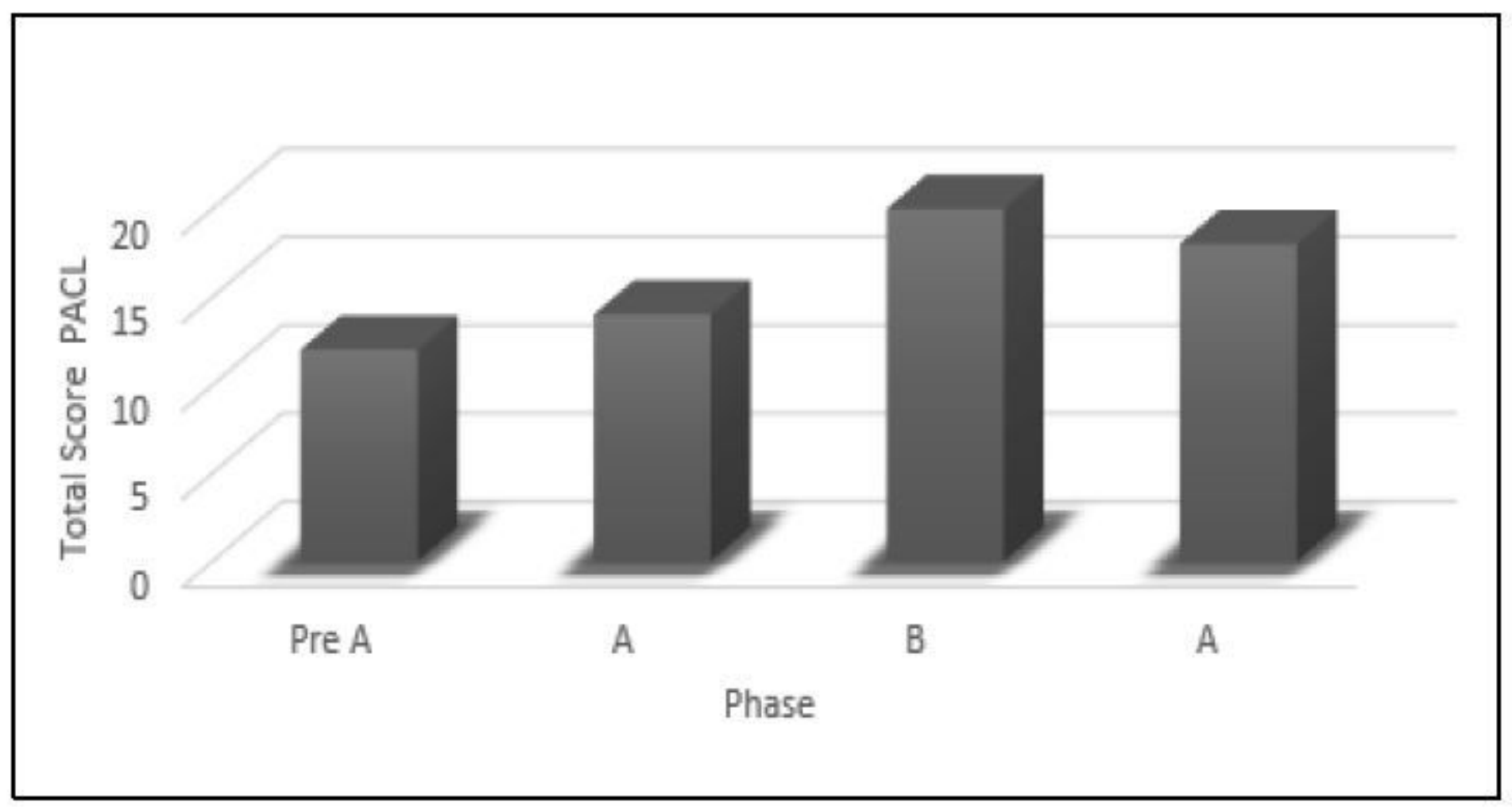

Figure 18

PACL scores per phase for P3. 